NBER WORKING PAPER SERIES

\title{
RETIREMENT POLICY AND ANNUITY MARKET EQUILIBRIA: EVIDENCE FROM CHILE
}

\author{
Gastón Illanes \\ Manisha Padi \\ Working Paper 26285 \\ http://www.nber.org/papers/w26285 \\ NATIONAL BUREAU OF ECONOMIC RESEARCH \\ 1050 Massachusetts Avenue \\ Cambridge, MA 02138 \\ September 2019
}

A previous version of this paper was circulated as "Competition, Asymmetric Information, and the Annuity Puzzle: Evidence from a Government-run Exchange in Chile." The research reported herein was performed pursuant to a grant from the U.S. Social Security Administration (SSA) funded as part of the Boston College Retirement Research Consortium. Padi acknowledges additional financial support from the Center for Equitable Growth and the National Science Foundation. The opinions and conclusions expressed are solely those of the authors and do not represent the opinions or policy of SSA, any agency of the federal government, or Boston College. The authors would like to thank Benjamin Vatter for outstanding research assistance, as well as Carlos Alvarado and Jorge Mastrangelo at the Superintendencia de Valores y Seguros and Paulina Granados and Claudio Palominos at the Superintendencia de Pensiones. We also thank Pilar Alcalde, Natalie Bachas, Vivek Bhattacharya, Ivan Canay, Liran Einav, Amy Finkelstein, Jerry Hausman, Igal Hendel, J.F. Houde, Koichiro Ito, Mauricio Larrain, Ariel Pakes, James Poterba, Mar Reguant, Nancy Rose, Casey Rothschild, Paulo Somaini, Salvador Valdes, Bernardita Vial and Michael Whinston for their useful comments, as well as numerous conference and seminar participants. The authors declare that they have no relevant or material financial interests that relate to the research described in this paper. The views expressed herein are those of the authors and do not necessarily reflect the views of the National Bureau of Economic Research.

NBER working papers are circulated for discussion and comment purposes. They have not been peer-reviewed or been subject to the review by the NBER Board of Directors that accompanies official NBER publications.

(C) 2019 by Gastón Illanes and Manisha Padi. All rights reserved. Short sections of text, not to exceed two paragraphs, may be quoted without explicit permission provided that full credit, including $(\odot$ notice, is given to the source. 
Retirement Policy and Annuity Market Equilibria: Evidence from Chile

Gastón Illanes and Manisha Padi

NBER Working Paper No. 26285

September 2019

JEL No. D15,D82,G22,G28,H31,H44

\begin{abstract}
$\underline{\text { ABSTRACT }}$
Retirement policy has indirect effects on its beneficiaries, through the "crowd-out" or "crowd-in" of insurance markets. We study how retirement policy in Chile, which limits the drawdown of retirement assets but otherwise does not provide or require fixed income in retirement, results in more than $60 \%$ of eligible retirees purchasing private annuities at low prices. We estimate a demand model to show that replacing this voluntary policy with partial mandatory annuitization and removing limits on drawdowns causes the private annuity market to partially unravel. Under our model, this reform leads to a welfare increase equivalent to US $\$ 4,000$ of additional pension savings on average, but welfare effects are heterogenous and many retirees would be harmed due to the higher prices of private annuities. Our results highlight the importance of considering the impact of policy reforms on the equilibria of related markets.
\end{abstract}

\author{
Gastón Illanes \\ Department of Economics \\ Northwestern University \\ Kellogg Global Hub, Room 3421 \\ 2211 Campus Drive \\ Evanston, IL 60208 \\ and NBER \\ gaston.illanes@northwestern.edu \\ Manisha Padi \\ UC Berkeley \\ 225 Bancroft Way \\ Berkeley, CA 94720 \\ mpadi@berkeley.edu
}

A data appendix is available at http://www.nber.org/data-appendix/w26285 
Governments leverage several policy tools to provide financial security to their retirees. Some publicly provide social insurance, while others require mandatory purchase of certain private insurance products. ${ }^{1}$ In the shadow of these policies, retirees will have different willingness to pay for private insurance, and the risk of the privately insured population may change. Equilibrium prices and transaction volumes in the private market will vary based on the government's regulatory approach, resulting in "crowd-in" or "crowd-out" of private purchases. The welfare impact of a policy, therefore, includes both its direct effect and its indirect effect on private market equilibria.

We study the relationship between private market outcomes and regulation in Chile, which allows a choice between private market annuitization and a regulated drawdown path of retirement savings. This voluntary policy requires neither mandatory purchase of private insurance nor does it provide a default "public option," providing a unique opportunity to observe active selection into a robust private insurance market without mandates. ${ }^{2}$ In the shadow of Chile's voluntary retirement policy, we observe many retirees purchasing private annuities at low prices. Our project studies the welfare of the entire distribution of retirees within this voluntary retirement system that crowds in a robust private market, relative to counterfactual policies that crowd-out private annuity markets.

Annuities have the attractive feature of insuring against longevity risk by providing a fixed income stream for the remainder of the annuitant's lifetime. Moreover, they can accommodate heterogeneous preferences across the retiree population by offering optional features such as guaranteed payments to the annuitant's heirs or delaying payments until a later age. Because of this, the previous literature has recognized this class of assets as potentially playing a central role in retirement income portfolios. Despite the theoretical benefits of annuitization, most households in the developed world choose not to purchase private market annuities. This phenomenon, often called

\footnotetext{
${ }^{1} \mathrm{~A}$ large literature explores the role of mandatory purchase of private insurance as an alternative or supplement to social insurance, including Crivelli, Filippini and Mosca (2006), Brown and Finkelstein (2008), Einav, Finkelstein and Schrimpf (2010), and Hackmann, Kolstad and Kowalski (2015).

${ }^{2}$ Some papers, including Rothschild (2009) and Hosseini (2015), study private insurance markets without any mandates or drawdown limits.
} 
the "annuity puzzle", has spurred a series of papers that attempts to explain retiree behavior. ${ }^{3}$

We explore an alternate explanation to the annuity puzzle - that mandatory public pension programs like Social Security crowd-out private annuity markets, while voluntary retirement policies crowd-in private markets.. ${ }^{4}$ To do so, we take advantage of the unique case study of Chile's privatized social security system. Using novel individual-level data on every annuity and programmed withdrawal offer provided on this platform from 2004 to 2012, every choice made, and mortality realizations until mid-2015, we document three key facts about the market for private annuities in Chile. First, over $60 \%$ of retirees in Chile purchase a private annuity, meaning that Chile is an exception to the annuity puzzle. Second, annuity prices are low: the average accepted annuity is $3 \%$ less generous than the actuarially fair annuity. Third, through the Chiappori and Salanie (2000) test for asymmetric information, we show that the Chilean equilibrium survives despite the presence of adverse selection. That is, the equilibrium in this system features low prices and high transaction volumes despite dealing with the same challenges facing most insurance markets.

We hypothesize that two features of the Chilean retirement policy drive crowd-in of the private market - the lack of mandatory annuitization, and the limits placed on the outside option to annuitization, namely drawdown of retirement assets. Since 2004, Chile has facilitated the sale of private annuities through a government-run exchange which does not require any retirees to purchase a fixed income product. The exchange is a virtual platform which transmits consumer information and preferences to all annuity providers (life insurance companies), solicits offers from any company willing to sell to that consumer, and organizes the offers by generosity to facilitate the retiree's decision process. Retirees may also choose not to purchase an annuity and instead to draw down the balance of their retirement savings account, according to a schedule set by the govern-

\footnotetext{
${ }^{3}$ Although this literature is very broad, some proposed explanations are adverse selection and high prices(Friedman and Warshawsky (1990), Butler and Teppa (2007), Mitchell et al. (1999)), behavioral biases (Davidoff, Brown and Diamond (2005), Bernartzi and Thaler (2011), Brown et al. (2017)), bequest motives (Lockwood (2012)) and uncertain health expenditures (Reichling and Smetters (2015))

${ }^{4}$ This has previously been discussed in the theory literature, including Caliendo, Guo and Hosseini (2014).
} 
ment. This alternative is called "programmed withdrawal". Relative to annuitization, programmed withdrawal allows retirees to leave more wealth for their heirs if they die early, and provides more liquidity early in retirement. Therefore, it is more valuable as a vehicle for bequests and liquidity, rather than as a source of insurance against longevity. In this setting, the government's role is primarily transmitting information between firms and consumers in the exchange, without limiting price discrimination or constraining consumer and firm choice, and in designing the outside option to annuitization.

We calibrate a life cycle model and calculate implied annuity demand and average cost curves to demonstrate crowd-in and crowd-out under the current Chilean system and alternatives. Chile's retirement policy, including the design of programmed withdrawal and the lack of mandatory social security, results in private market annuity demand that is relatively inelastic. In contrast, introducing mandatory partial annuitization at the actuarially fair rate and allowing retirees to allocate their remaining savings between lump sum withdrawal and a private market annuity leads to more elastic annuity demand. That means average cost increases faster than willingness to pay for annuities, leading to a market with lower levels of annuitization. There are three main forces behind this change: first, willingness to pay for each annuitized dollar mechanically decreases for the whole population when a significant fraction of wealth is pre-annuitized, and as a result demand contracts; second, this effect is heterogenous across retirees, depending on their underlying preferences for financial instruments, so that demand rotates; and third, these reforms can affect which individuals annuitize at a given annuity payout, and how much they annuitize, so that the average cost curve shifts. Additionally, the calibration also demonstrates two important features of the setting that motivate our econometric model. First, that the relationship between mortality and other drivers of preferences for financial instruments, such as bequest motives and risk aversion, can greatly affect annuity market equilibria. ${ }^{5}$ Second, that average cost and demand are non-linear, and as a result linear approximations to these objects will be inaccurate for large-scale counterfactuals, such as

\footnotetext{
${ }^{5}$ Building on work such as Finkelstein and McGarry (2006) and Einav, Finkelstein and Schrimpf (2010).
} 
the ones we are interested in studying.

To quantify the impact of changes in retirement policy on private market equilibria, we estimate a structural model that traces out the demand curve for annuities in Chile. Our model allows us to nonparametrically estimate the distribution of private information in the market. The model proceeds in two steps. First, we discretize the space of unobserved heterogeneity and solve an optimal consumption-savings problem to value every annuity and programmed withdrawal offer for every combination of unobserved heterogeneity or type. We then use the estimator presented in Fox et al. (2011) and Fox, il Kim and Yang (2016) to non-parametrically estimate the distribution of types that rationalizes observed choices. The main advantage of this approach relative to other demand estimation techniques is that our consumption-savings model allows us to value out-ofsample financial contracts and to predict choices type-by-type, while the estimated distribution of types allows us to aggregate and predict private market equilibria. We then calculate welfare changes for each consumer type taking into account equilibrium price responses.

Demand estimates highlight that there is significant unobserved heterogeneity among retirees, even after conditioning on observables. Moreover, we find evidence of correlations across dimensions of unobserved heterogeneity. Using the estimated distribution of unobserved types, we show that the design of the Chilean retirement system does in fact crowd-in the private market, since moving to counterfactual retirement policies leads to lower annuitization rates and higher prices. First, we simply increase the value of the outside option for every type of retiree by removing limits on retirement savings drawdown. This crowds out the private market by lowering willingness to pay for private annuities, resulting in lower transaction volume and higher prices. Having access to a better outside option therefore lowers the welfare of those who continue to purchase private annuities. Although the average welfare change is positive, we find that $45 \%$ of retirees have lower welfare from this reform due to the equilibrium response of the private annuity market.

More significant crowd-out is observed when retirement policy includes mandatory retirement 
income, similar to publicly provided Social Security or mandatory purchases of private annuities as in the UK. Moving to a mandatory policy further lowers willingness to pay for additional annuitized wealth, causing significantly higher private annuity prices and a larger drop in annuitized wealth. Under this counterfactual policy regime, we can generate the same low annuitization levels described in the annuity puzzle literature. Despite this, we find that on average retirees would experience a welfare increase equivalent to an additional $\$ 4,000$ dollars of pension savings under this reform. This average masks substantial heterogeneity and redistribution across dimensions of unobserved type. A crowded-out private annuity market in the presence of mandatory public retirement policy significantly lowers welfare for about $25 \%$ of retirees, but it does generate higher welfare for a majority of our population.

\section{Related Literature}

This work brings together two strands of the literature. The first is the literature on crowdout and the interaction between public policy and private markets. Starting with Cutler and Gruber (1996), researchers have documented how public spending crowds out private insurance. Examples include unemployment benefits (Cullen and Gruber (2000)), public health insurance (Cutler and Gruber (1996), Sloan and Norton (1997), Gruber and Simon (2008)), long term care insurance (Brown, Coe and Finkelstein (2007), Brown and Finkelstein (2008)), and emergency care and bankruptcy (Koch (2014), Mahoney (2015), Garthwaite, Gross and Notowidigdo (2018)). This work generally shows that public policy can impact private markets, but stops short of modeling and estimating private market primitives and therefore cannot compute welfare effects of large scale policy reforms. Hosseini (2015) and Caliendo, Guo and Hosseini (2014) uses calibrated theory models to demonstrate the potential impact of retirement policy in private annuity markets.

We connect this literature to the second strand of scholarship, modeling and estimating equi- 
librium in markets with asymmetric information using data on insurance purchases. We start with a structural model to back out the distribution of retirees' private information, based on Einav, Finkelstein and Schrimpf (2010). We take a more primitive approach to modeling demand than other papers on publicly supported private insurance markets, including Medigap (Bundorf and Simon (2006), Starc (2014), Keane and Stavrunova (2016)) and state health insurance exchanges (Finkelstein, Hendren and Shepard (2017), Einav, Finkelstein and Tebaldi (2019) Tebaldi (2019)). To this literature we add heterogeneity in risk preference and outside wealth. Our contribution is to nonparametrically identify private information without making any assumptions on firm pricing behavior. We also solve for counterfactual equilibria when significant changes are made to retirement policy, and when the product set changes, accounting for equilibrium effects.

The rest of the paper is structured as follows: section 1 introduces the main features of the Chilean retirement exchange; section 2 presents descriptive evidence on the functioning of this system; section 3 develops the lifecycle model of consumption and savings used for both calibrations and demand estimation; section 4 uses a calibration to show how differences in regulation shift demand and average cost functions even with the same primitives; section 5 presents our demand estimation framework, provides details on the empirical implementation, and discusses identification; section 6 estimates the distribution of underlying types and uses demand estimates to simulate counterfactual annuity market equilibria and welfare under different regulatory regimes; and section 7 concludes.

\section{The Chilean Retirement Exchange}

Chile has a privatized pension savings system. Individuals who are employed in the formal sector must contribute $10 \%$ of their income to a private retirement savings account administered by a Pension Fund Administrator (PFA). In order to access the accumulated balance upon retire- 
ment, retirees must utilize a government-run exchange called "SCOMP"6. The exchange can be accessed either through an intermediary, such as an insurance sales agent or financial advisor, or directly by the individual at a pension fund administrator. Individuals can enter SCOMP at any time after they have accumulated more wealth than a legal minimum. In practice, since the minimum wealth requirement falls significantly after certain age thresholds (60 for women and 65 for men), most retirees enter the exchange at that point or after. Individuals provide the exchange with their demographic information, private savings account balance, and the types of annuity contracts they want to elicit offers for (choices are deferral of payments, purchase of a guarantee period to provide payouts after death, fraction of total wealth to annuitize ${ }^{7}$, and transitory rents, an annuity with a front-loaded step function).

There are between 13 and 15 firms participating in this exchange between 2004 and 2013. Once an individual enters the exchange, each firm simultaneously receives the following information: gender, age, marital status, age of the spouse, number and age of legal beneficiaries other than the spouse, pension account balance, and the set of contracts for which offers have been requested. ${ }^{8}$ Armed with this information, each firm sets individual and contract type specific offers. They can also not bid on some or all of the contracts the individual requested. There is no regulation impeding price discrimination based on any of the characteristics firms observe through SCOMP. There is, however, the requirement that all bids be denominated in an inflation indexed unit of account (Shiller (1998)) called "Unidad de Fomento" (UF), so all annuities in this setting are measured in real currency. ${ }^{9}$

Retirees can opt not to accept an annuity offer, but instead to take an alternative product, called programmed withdrawal ("PW") ${ }^{10}$. Programmed withdrawal provides a front-loaded drawdown of

\footnotetext{
${ }^{6}$ Sistema de Consultas y Ofertas de Montos de Pensión.

${ }^{7}$ With significant restrictions. In our sample, fewer than $10 \%$ of retirees were eligible to not annuitize their total savings

${ }^{8}$ Other beneficiaries include children under 18 ( 25 if they are attending college)

${ }^{9}$ In December 12, 2017, a UF was worth 40.85 USD

${ }^{10}$ All individuals who accept PW are still included in our sample.
} 
Figure 1: A simulated path of payments made under PW to a retiree who retires at 60, compared to the average annuity that retiree is offered

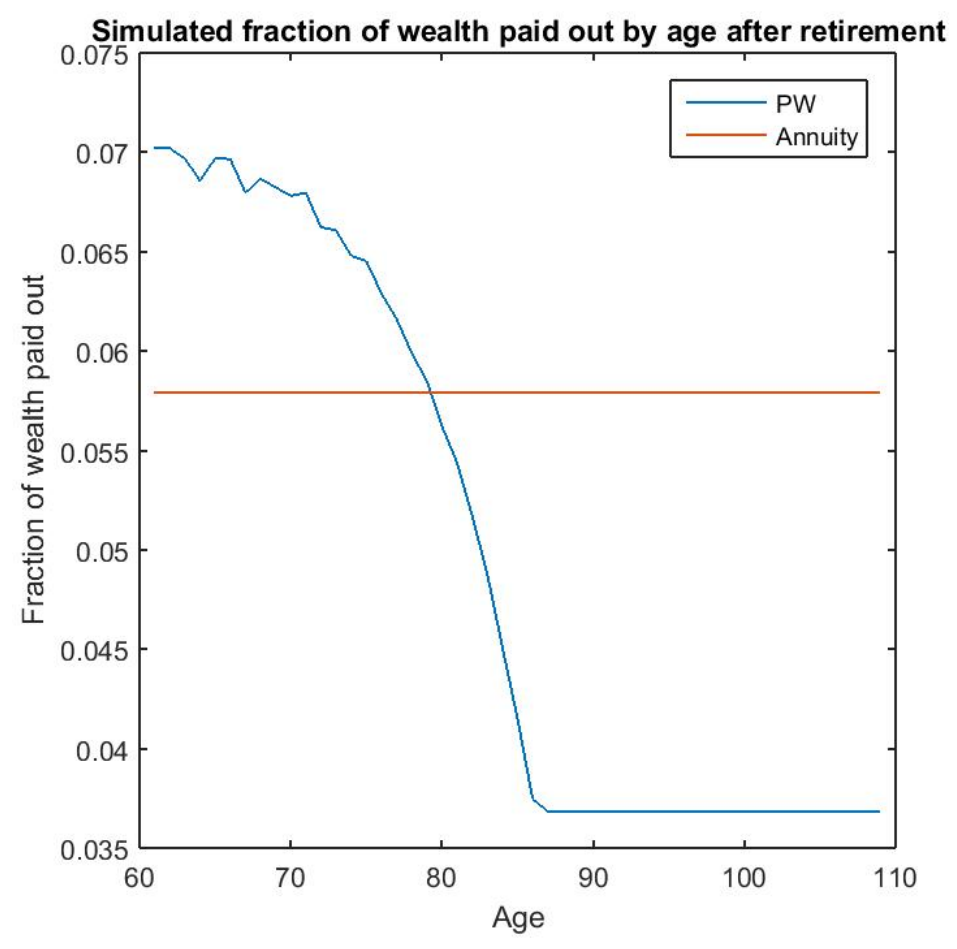

pension account funds according to a regulated schedule, with two key provisions. First, whenever the retiree dies, the remaining balance in their savings account is given to their heirs. Second, if the retiree is sufficiently poor and lives long enough for payments to fall below a minimum pension, the government will top up PW payments to reach this minimum level. ${ }^{11}$ When an individual chooses the PW option, their retirement balance remains at a PFA, which invests it in a low risk fund. As a result, PW payments are stochastic, although the variance is small. Figure 1 shows one realization of PW payments for a female who retires at 60, and compares it to the average annuity offer that individual received.

Retirees receive all annuity offers and information about PW on an informational document provided by SCOMP. The document begins with a description of programmed withdrawal and a

\footnotetext{
${ }^{11}$ The threshold for receiving the minimum pension is being below the $60 \%$ percentile of total wealth according to the "Puntaje de Focalización Previsional"
} 
Figure 2: Sample printout of programmed withdrawal information conveyed to retiree

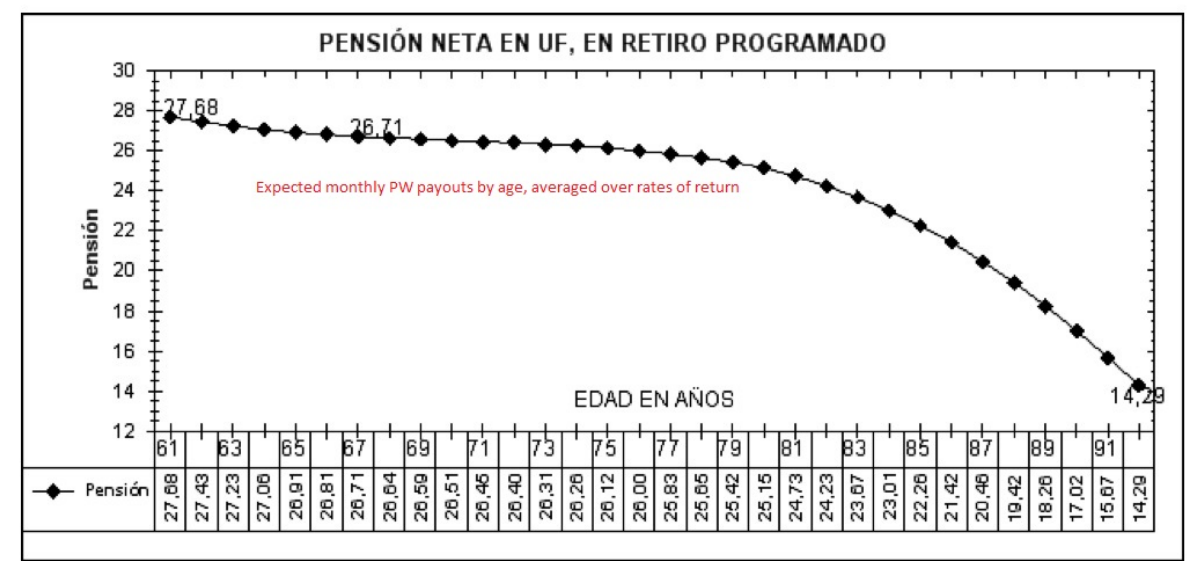

Monto Pensión mensual promedio: 24,18 UF

Monto Comisión mensual promedio: 0,30 UF

sample drawdown path (figure 2). Then, annuity offers are listed, ranked within contract type first by generosity (figure 3). Along with the life insurance company's name, retirees are also informed of their risk rating. This information is relevant, as retirees are only partially insured against the life insurance company going bankrupt. ${ }^{12}$

After receiving this document, retirees can accept an offer or enter a bargaining stage. Retirees can physically travel to any subset of firms that gave them offers through SCOMP to bargain for a better price, for some or all of the contracts they are interested in. ${ }^{13}$ On average, these outside offers represent a modest increase in generosity over offers received within SCOMP, on the order of $2 \%$. Finally, the individual can choose either to buy an annuity from the final choice set or to take PW. Individuals that don't have enough retirement wealth to fund an annuity above a minimum threshold amount per month will receive no offers from firms, and must take PW.

\footnotetext{
${ }^{12}$ To be precise, the government fully reinsures the MPG plus $75 \%$ of the difference between the annuity payment and the MPG, up to a cap of 45 UFs. In practice, there has been only one bankruptcy since the private retirement system's introduction in the 1980s, and that company's annuitants received their full annuity payments for 124 months after bankruptcy was declared. Only after that period did their payments fall to the governmental guarantee. Alcalde and Vial (2017) study willingness-to-pay for different product attributes, including risk rating, finding that individuals are on average willing to give up around $1 \%$ of the offer value to accept an offer from a AA+ or better rated firm.

${ }^{13}$ Firms are not allowed to lower their offers in this stage
} 
Figure 3: Sample printout of annuity offers for one contract type

\section{MODALIDAD RENTA VITALICIA INMEDIATA}

\begin{tabular}{|c|c|c|c|c|c|c|}
\hline \multirow[t]{2}{*}{$\mathrm{N}^{\circ}$ Oferta } & \multirow{2}{*}{$\begin{array}{l}\text { Compania de Seguros de Vida } \\
\text { Brand Name }\end{array}$} & \multirow{2}{*}{$\begin{array}{l}\text { Pensión final } \\
\text { Mensual sin } \\
\text { Retiro de } \\
\text { Excedente } \\
\text { UF }\end{array}$} & \multirow{2}{*}{$\begin{array}{l}\text { Pensión final Mensual en UF } \\
\text { Considerando un retiro de } \\
\text { excedente de } 0,00 \text { UF }\end{array}$} & \multicolumn{2}{|c|}{$\begin{array}{l}\text { Pensión con retiro de } \\
\text { Excedente Máximo }\end{array}$} & \multirow{2}{*}{$\begin{array}{l}\text { Clasificación de } \\
\text { riesgo de la } \\
\text { Compañía de } \\
\text { Seguros } \\
\text { (2) }\end{array}$} \\
\hline & & & & $\begin{array}{l}\text { Pensión final } \\
\text { Mensual UF }\end{array}$ & $\begin{array}{c}\text { Excedente } \\
\text { UF }\end{array}$ & \\
\hline 43872093 & CRUZ DEL SUR & 26,61 & <- Monthly payment & & Risk rating $->$ & AA- \\
\hline 43872099 & RENTA NACIONAL & 26,58 & & & & BBB- \\
\hline 43872083 & METLIFE & 26,52 & & & & AA \\
\hline 43872100 & CORPSEGUROS & 26,34 & & & & AA- \\
\hline 43872094 & PRINCIPAL & 26,28 & & & & AA \\
\hline 43872097 & CORPVIDA & 26,26 & & & & AA- \\
\hline 43872084 & EUROAMERICA VIDA & 26,25 & & & & AA- \\
\hline 43872090 & PENTA VIDA & 26,25 & & & & AA- \\
\hline 43872091 & OHIO NATIONAL & 26,24 & & & & AA \\
\hline 43872098 & SURA & 26,21 & & & & AA \\
\hline 43872095 & CN LIFE & 25,90 & & & & AA \\
\hline 43872092 & BICE VIDA & 25,86 & & & & $\mathrm{AA}+$ \\
\hline 43872085 & CHILENA CONSOLIDADA & 25,59 & & & & AA \\
\hline 43872086 & CONSORCIO VIDA & 25,36 & & & & $\mathrm{AA}+$ \\
\hline
\end{tabular}

Our primary source of data is the individual-level administrative dataset from SCOMP from 2004 to 2013, which includes the retiree's date of birth, gender, geographic location, wealth, and beneficiaries. This data includes contract-level information about prices, contract characteristics and firm identifiers. We observe the contract each retiree chooses, including if they choose not to annuitize, and can compare the characteristics of the chosen contract to the other choices they had, including offers received during the bargaining stage. Overall, we observe 230,000 retirees and around 30 million annuity offers. We supplement this data with two external datasets. First, we include external data about the life insurance companies making offers, such as their risk rating ${ }^{14}$. Second, we merge individual-level death records obtained from the Registro Civil in mid 2015.

Throughout our sample period, annuity contracts for married males are regulated to be joint life annuities, while this is only the case for married females after 2007. Furthermore, for retirees with children younger than 18 , life insurance companies must continue paying out a fraction of the annuity payment upon the retirees' death until the child turns $18 .{ }^{15}$ For ease of calculation, we will focus our analysis on the subsample of retirees with no beneficiaries. This subsample purchases

\footnotetext{
${ }^{14}$ While this variable is presented to retirees, it was not made available to us directly in the SCOMP dataset.

${ }^{15}$ Children younger than 25 are also covered if they are in college, until either they graduate or turn 25.
} 
Table 1: Average characteristics of our sample and of accepted annuity contracts

\begin{tabular}{lccccc}
\hline \hline & $\mathrm{N}$ & Mean & 10th Pctile & Median & 90th Pctile \\
\cline { 2 - 6 } & & & & & \\
Panel A: Retiree Characteristics & & & & & \\
\hline Total wealth (UFs) & 45091 & 2378.488 & 937.42 & 1958.91 & 4190.91 \\
Female (dummy) & 45091 & 0.759 & 0 & 1 & 1 \\
Age & 45091 & 62.566 & 60 & 62 & 66 \\
Married & 45091 & 0.207 & 0 & 0 & 1 \\
Insurance agent & 45091 & 0.284 & 0 & 0 & 1 \\
Died in two years & 45091 & 0.016 & 0 & 0 & 0 \\
Choose annuity & 45091 & 0.688 & 0 & 1 & 1 \\
& & & & & \\
Panel B: Contract Characteristics & & & & & \\
Choose dominated offer & 31062 & 0.194 & 0 & 0 & 1 \\
Monthly payment (UFs) & 31062 & 11.132 & 5.08 & 9.26 & 19.06 \\
Deferral years & 31062 & 0.532 & 0 & 0 & 2 \\
Guarantee months & 31062 & 124.873 & 0 & 120 & 216 \\
Money's worth ratio & 31062 & 1.00288 & 0.9445 & 1.0050 & 1.0740 \\
& & & & & \\
\hline
\end{tabular}

only single life annuities that insure their own longevity risk. Our final dataset consists of 53,356 individuals who receive annuity offers and accept either programmed withdrawal or an annuity within our sample period.

Table 1 presents summary statistics for this sample. Panel A reports statistics for all individuals, while Panel B reports statistics of accepted annuity offers. The annuitization rate for this sample is $68.8 \%$, and the probability of death by two years after retirement is $1.6 \%$. Note that a disproportionate fraction of our sample is female, as all women without eligible children (including those with living spouses) who retired on or before 2007 were limited to single life annuities. Roughly $28 \%$ of the individuals in the sample entered their information into SCOMP through an agent of a life insurance company, and $19.4 \%$ of accepted annuity offers are dominated. ${ }^{16}$ There is significant heterogeneity across accepted guarantee periods and deferral periods, with most individuals accepting immediate annuities and a median guarantee period of 10 years.

\footnotetext{
${ }^{16}$ We call an offer dominated if there is another offer of the same contract type with weakly better risk rating and a higher payout amount
} 
Figure 4: Contracts accepted by subsample of retirees, where the leftmost bar represents programmed withdrawal and the others refer to annuities sold by the top 10 annuity providers

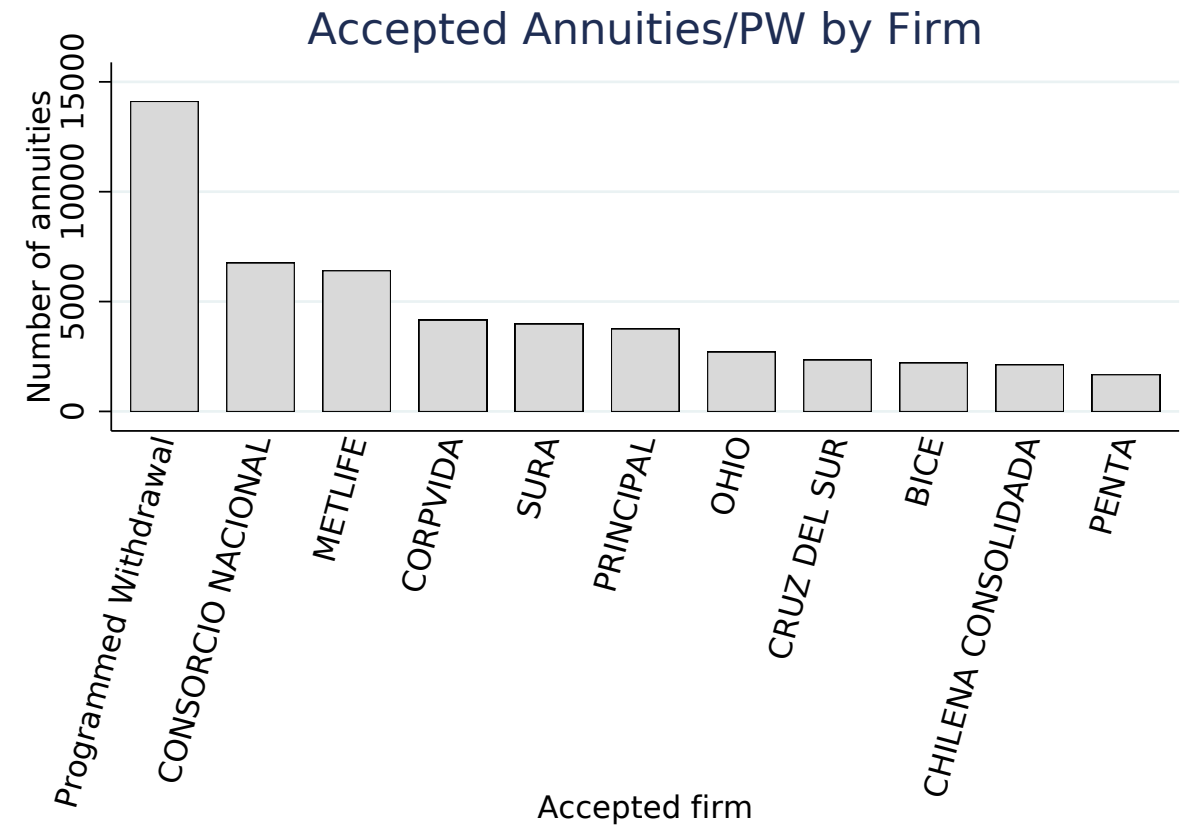

\section{Descriptive Evidence}

There are three striking facts from the annuities market in Chile that emerge from descriptive analysis. First, the fraction of individuals voluntarily choosing annuities is high - nearly $70 \%$ of retirees choose an annuity. Second, the market for annuities is fairly unconcentrated, with each of the top ten firms getting a significant share of annuitants (figure (4)). And third, retirees receive annuity offers that are marked up on average only by $5 \%$ over the actuarially fair annuity calculated using the distribution of mortality observed in the data, although there is significant heterogeneity in the population over these markups. 


\section{Calculating Annuity Value}

We calculate actuarially fair annuities by modelling the hazard rate of death $\left(h_{j}(t)\right)$ as a Gompertz distribution with a different scale parameter for each demographic type $j$ (bins of age, gender, municipality, and wealth level). The shape parameter $\gamma$ is fixed and the scale parameter is modeled as $\lambda_{j}=e^{x_{j} \beta}$. The resulting hazard rate is given by:

$$
h_{j}(t)=\lambda_{j} e^{\gamma t}
$$

Since we observe death before 2015, we can estimate this model directly for our sample. Using the results of this estimation, we can predict expected mortality probabilities for each individual and calculate the net present cost of an annuity with a monthly payout $z_{t}$, discounted at rate $r$. The predicted survival probabilities (dependent on age, gender, wealth, and municipality) are denoted as $\left\{\hat{\pi}_{i t}\right\}$. The NPV of an annuity can then be calculated as:

$$
N P V\left(z_{i}\right)=\sum_{t=0}^{T} \frac{\hat{\pi}_{i t} z_{i}}{(1+r)^{t}}
$$

Naturally, the value of the annuity payout depends on the total retirement savings the retiree gives the life insurance company (denoted by $w_{i}$ ). We calculate percentage markup over cost as:

$$
m_{i}=\frac{w_{i}-N P V\left(z_{t}\right)}{N P V\left(z_{t}\right)}=\frac{1}{M W R_{i}}-1
$$

A first pass at comparing the value of annuities relative to $\mathrm{PW}$ is to repeat the exercise done in prior literature, which solves for the ratio of offered annuity NPV to the total amount of wealth transferred to the insurance company. This amount is the money's worth ratio ("MWR"). Mitchell et al. (1999) perform this calculation for US retirees without a bequest motive facing actuarially 
fair annuities, and find an MWR of between 0.82 and $0.92 .{ }^{17}$ We find that in our context, offered annuities have a markup of about $5 \%$ over actuarially fair, which translates to a MWR of 0.952. Accepted annuities have a markup of about $3 \%$ over actuarially fair, or a MWR of 0.97 . Prices in the Chilean market are therefore significantly lower than in other countries.

\section{Selection}

Though the market appears to be functioning remarkably well, there is significant adverse selection in annuity purchase. To demonstrate this, we run the standard positive correlation test, introduced by Chiappori and Salanie (2000). In our implementation of this test, we regress the probability the retiree dies within two years of retirement, regressed on a dummy for annuity choice. Table 2 shows this baseline correlation in column 1. Columns 2 and 3 check the robustness of the result after controlling for observable characteristics of the individual and the requests the individual makes for annuity offers. This is the full set of information life insurance companies receive about retirees. We use the estimating equation:

$$
d_{\text {death }, i}=\gamma_{\text {annuitize }} d_{\text {annuitize }, i}+X^{\prime} \Pi_{D}
$$

Covariates $X$ include all characteristics that firms may price on. The purpose of including controls is to make sure that selection is on unobservable characteristics - selection on observable characteristics can be reflected by a change in price, while selection on unobservables cannot be. A negative correlation means that retirees buying annuities are less likely to die than retirees that choose programmed withdrawal. Results show that annuitants are significantly more long lived than those choosing programmed withdrawal, even conditional on characteristics that firms can

\footnotetext{
${ }^{17} \mathrm{We}$ consider the before-tax values in their calculation for policies offered to men aged 65 , which would be more generous than our population, where the modal annuitant is a 60 year old female.
} 
Table 2: Chiappori \& Salanie positive correlation test

\begin{tabular}{lccc}
\hline \hline & $(1)$ & $(2)$ & $(3)$ \\
& Death by 2 yrs & Death by 2 yrs & Death by 2 yrs \\
\cline { 2 - 4 } Choose annuity & $-0.00740^{* *}$ & $-0.00399^{* *}$ & $-0.00434^{* *}$ \\
& $(0.00137)$ & $(0.00137)$ & $(0.00156)$ \\
& & $\checkmark$ & $\checkmark$ \\
Individual characteristics & & & $\checkmark$ \\
$\begin{array}{l}\text { Request characteristics } \\
\text { Observations }\end{array}$ & 45091 & 45091 & 45091 \\
Base group mean & & 0.015 & \\
& & $(0.121)$ & \\
\hline
\end{tabular}

price on. To put this number in context, we run the correlation test using a Gompertz hazard model (reported in figure 16 in Appendix C). From this, we can estimate the relative life expectancies of annuitants, separately from non-annuitants. For a modal population of female retirees in 2010, retiring without help from an intermediary, we estimate that annuitants live on average 7 months longer than non-annuitants.

Despite the standard concerns regarding adverse selection, Chile's regulatory regime supports the existence of a healthy voluntary annuity market. Our goal is to estimate the primitives governing demand for these products, and to then simulate how reforming the Chilean regulatory framework to make it more similar to the US shifts the market equilibrium. The following section introduces the model we will use to value each contract.

\section{Model}

This section develops a model to value annuity and programmed withdrawal offers given a vector of individual characteristics and unobserved preferences. In section 5, we will embed the model into a discrete choice demand system to obtain estimates of unobserved preferences, and use these estimates to evaluate counterfactuals where we change the regulatory environment. The 
primary contribution of this model is to account for multiple dimensions of retiree private information, allowing preferences to be far more heterogeneous than in prior work. Specifically, the model allows for private information about mortality risk, bequest motives, risk aversion, and total wealth.

Since individuals are making choices over financial instruments that differentially shift money over time, change exposure to longevity risk, and vary the assets that are bequeathed upon death, a suitable model needs to capture these salient features. In particular, we use a finite-horizon consumption-savings model with mortality and bankuptcy risk and the potential for utility derived from inheritors' consumption. Consider the problem of a particular individual who faces a set of annuity and programmed withdrawal offers. To obtain the value of each offer, the individual needs to solve for the optimal state-contingent consumption path, taking into account uncertainty about their own lifespan and about the probability that each life insurance firm will go bankrupt.

Before introducing the individual's optimization problem, some additional notation is needed. Fix an individual and firm, so we can suppress those subscripts. Let $t=0$ denote the moment in time when the individual retires, and let $T$ denote the terminal period in our finite horizon problem. Let $\omega$ denote outside wealth (the amount of assets held outside the pension system), $\gamma$ denote risk aversion, and $\delta$ denote the discount factor. Let $d_{t}=\{0,1\}$ denote whether the individual is alive (0) or dead (1) in period $t$, and $\left\{\mu_{\tau}\right\}_{\tau=1}^{T}$ denote the vector of mortality probabilities ${ }^{18}$. Following Carroll (2011), let $c_{t}$ denote consumption in period $t, m_{t}$ the level of resources available for consumption in $t, a_{t}$ the remaining assets after $t$ ends, and $b_{t+1}$ the "bank balance" in $t+1$.

For the purposes of specifying the optimal consumption-savings problem given an annuity offer, we also need to define $q_{t}$, which denotes whether the firm is bankrupt (1) or not (0) in period $t$, and the vector of bankruptcy probabilities for the offering firm $\left\{\psi_{j, \tau}\right\}_{\tau=1}^{T}{ }^{19}$. With these objects,

\footnotetext{
${ }^{18}$ Clearly, $d_{0}=0$ and $\mu_{0}=0$

${ }^{19}$ Naturally $q_{0}=0$ and $\psi_{0}=0$
} 
we can write the annuity payment in period $t$ conditional on $d_{t}, q_{t}$, the deferral period $D$ and the guarantee period $G$ as $z_{t}\left(d_{t}, q_{t}, D, G\right)$.

With this notation, and suppressing individual and firm subscripts, we can write the individual's optimal consumption problem given an annuity offer as:

$$
\begin{array}{cr}
\max & E_{0}\left[\sum_{\tau=0}^{T} \delta^{\tau} u\left(c_{\tau}, d_{\tau}\right)\right] \\
\text { s.t. } & \\
a_{t}=m_{t}-c_{t} \quad \forall t & b_{t+1}=a_{t} \cdot R \quad \forall t \\
m_{t+1}=b_{t+1}+z_{t+1}\left(d_{t+1}, q_{t+1}, D, G\right) \quad \forall t \quad a_{t} \geq 0 \quad \forall t
\end{array}
$$

Where $R=1+r$, and $r$ is the real interest rate, which we assume is deterministic and fixed over time. ${ }^{20}$ Note that we are imposing a no borrowing constraint: there can be no negative end of period asset holdings. This assumption greatly simplifies the problem from a computational perspective. In practice, life insurance companies can offer loans against their annuity payments, but only do so for five year terms and at interest rates exceeding $20 \%$, so we do not believe this assumption to be too restrictive. 21

\footnotetext{
${ }^{20}$ Annuity and PW offers in Chile are expressed in UFs, an inflation-adjusted currency, so everything in the model is in real terms.

${ }^{21}$ It is also increasingly difficult to keep a checking account, credit cards, and home loans open as individuals age. For example, see (in Spanish) http://www.emol.com/noticias/Nacional/2018/07/04/912082/Pinera-anuncia-queterminara-con-discriminacion-por-edad-en-servicios-bancarios-que-afecta-a-adultos-mayores.html
} 
The exogenous variables evolve as follows:

$$
\begin{aligned}
& m_{0}= \omega, d_{0}=0, q_{0}=0 \\
& d_{t+1}=\left\{\begin{array}{l}
0 \text { with probability }\left(1-\mu_{t+1}\right) \text { if } d_{t}=0 \\
1 \text { with probability } \mu_{t+1} \text { if } d_{t}=0 \\
1 \text { if } d_{t}=1
\end{array}\right. \\
& q_{t+1}=\left\{\begin{array}{l}
1 \text { with probability } \psi_{t+1} \text { if } q_{t}=0 \\
1 \text { if } q_{t}=1
\end{array}\right. \\
& z_{t}\left(d_{t}, q_{t}, D, G\right)=\left\{\begin{array}{l}
\rho \text { if } q_{t}=0 \text { and }\left(\left(d_{t}=0 \text { and } t \geq D\right) \text { or }\left(d_{t}=1 \text { and } D \leq t<G+D\right)\right) \\
\rho(z, t) \cdot z \text { if } q_{t}=1 \text { and }\left(\left(d_{t}=0 \text { and } t \geq D\right) \text { or }\left(d_{t}=1 \text { and } D \leq t<G+D\right)\right) \\
0 \text { otherwise }
\end{array}\right.
\end{aligned}
$$

Where $\rho(z, t)$ is the annuity payment when the firm goes bankrupt:

$$
\rho(z, t)= \begin{cases}M P G_{t} & \text { if } z \leq M P G_{t} \\ M P G_{t}+\min ((z-M P G) * 0.75,45) & \text { if } z>M P G\end{cases}
$$

and $M P G$ is the minimum pension guarantee. For the purposes of this model, we will assume that the MPG is fixed over time. Assume that the utility derived from consumption when alive is given by the following CRRA utility function:

$$
u\left(c_{t}, d_{t}=0\right)=\frac{c_{t}^{1-\gamma}}{1-\gamma}
$$


whereas if the individual dies at the beginning of period $t$, her terminal utility at $t$ is given by evaluating the CRRA at the expected value of remaining wealth:

$$
u\left(d_{t}=1\right)=\beta \cdot \frac{\left(m_{t}+E\left[\sum_{\tau=t+1}^{G} \delta^{t-\tau} z_{\tau}\left(1, q_{\tau}, D, G\right)\right]\right)^{1-\gamma}}{1-\gamma}
$$

and is equal to zero thereafter. ${ }^{22}$

To obtain the value of an annuity offer, which is the present discounted value of the expected utility of the optimal state-contingent consumption path, we solve this problem by backward induction. At the terminal period, the problem is simple and has an analytic solution, but for periods earlier than $T$ it must be solved numerically. We use the Endogenous Gridpoint Method (EGM) (Carroll (2006)) to solve this problem, obtaining $V^{A}(0,0 ; \pi)$, the present discounted value of the expected utility of consumption obtained from following the optimal state-contingent policy path given an annuity offer and the vector $\pi$ of parameters $^{23}$. See Appendix D for the full derivation of the Euler equations and the computational details of the numerical solution.

Valuing a programmed withdrawal (PW) offer requires solving a slightly different problem. In this setting there is no deferral or guarantee period, or bankruptcy risk for the asset. Furthermore, inheritors automatically receive all remaining balances as a bequest upon death. All of these factors simplify the problem relative to the annuity problem. Taking these differences into account, the individual's PW optimization problem, which gives us the value of accepting a PW offer from firm

\footnotetext{
${ }^{22}$ This assumption implies that individuals are not risk averse about the remaining uncertainty after death. If they were, we would need to calculate expected utility instead of the utility of the expectation. From a practical perspective, this is unlikely to matter much, as the only case where remaining wealth is stochastic is for annuity offers with a guarantee period from firms who have not gone bankrupt, as wealth left to inheritors in this case is still subject to bankruptcy risk. Since bankruptcy risk is small, and most deaths will occur after the guarantee period expires, we are comfortable making this assumption.

${ }^{23}$ Outside wealth $\omega$, bequest motive $\beta$, mortality probabilities $\{\mu\}_{t=1}^{T}$, risk aversion $\gamma$, and bankruptcy probabilities $\{\psi\}_{t=1}^{T}$
} 
$a$, is:

$$
\begin{array}{cr}
\max E_{0}\left[\sum_{\tau=0}^{T} \delta^{\tau} u\left(c_{t}, d_{t}\right)\right] & \\
\text { s.t. } & \\
a_{t}=m_{t}-c_{t} \forall t & b_{t+1}=a_{t} \cdot R_{t+1} \forall t \\
& m_{t+1}=b_{t+1}+z_{t+1}\left(P W_{t+1}, d_{t+1}, f\right) \forall t \\
\quad a_{t} \geq 0 \forall t
\end{array}
$$

where $z_{t}\left(P W_{t}, d_{t}, f\right)$ denotes the programmed withdrawal payout in period $t$ conditional on pension balance $P W_{t}$, death status, and $f$, the commission rate charged by the firm. The death state and initial conditions are as before, and the remaining exogenous variables evolve as follows:

$$
\begin{aligned}
z_{t}\left(P W_{t}, d_{t}, a\right) & =\left\{\begin{array}{l}
\max \left[z_{t}\left(P W_{t}\right) \cdot(1-f), M P G\right] \text { if } d_{t}=0 \\
0 \text { if } d_{t}=1
\end{array}\right. \\
P W_{t+1} & =\left(P W_{t}-z_{t}\left(P W_{t}\right)\right) \cdot R_{t}^{P W}
\end{aligned}
$$

The PW payout function $z_{t}\left(P W_{t}\right)$ is described in detail in Appendix A. All PFAs are governed by the same PW function, and conditional on the PW balance, will pay out the same amount up before the commission $f$. As a result, if PFAs provided the same returns over time, the amount of money that is withdrawn every year from the PW account would be the same across PFAs, and only how that money is distributed between the retiree and the PFA would vary across companies. We will assume that in fact PFAs provide the same returns on PW investments, as this simplifies the problem and is not far from reality, where PFA returns vary slightly for the safe investment portfolios where PW balances are invested ${ }^{24}$. Let $R_{t}^{P W}$ be the return to programmed withdrawal investments. Finally, MPG is the minimum pension guarantee. Every individual who takes PW is guaranteed a payout of at least $M P G$, and the difference between $z_{t}\left(P W_{t}\right)$ and $M P G$ (when

\footnotetext{
${ }^{24}$ Illanes (2019) documents this in detail
} 
$\left.z_{t}\left(P W_{t}\right)<M P G\right)$ is funded by the government. Finally, utility derived from consumption is as before, while upon death utility is:

$$
u\left(d_{t}=1\right)=\beta \cdot \frac{\left(m_{t}+P W_{t}\right)^{1-\gamma}}{1-\gamma}
$$

As for annuities, we solve this problem numerically by backwards induction using EGM, and obtain $V^{P W}\left(0, P W_{0} ; \pi\right)$, the present discounted value of the expected utility of consumption obtained from following the optimal state-contingent policy path given an initial PW balance of $P W_{0}$ and the vector $\pi$ of parameters. See Appendix D for the full derivation of the Euler equations and the computational details of the numerical solution.

\section{Calibration}

In this section, we calibrate the previous life cycle model and calculate the value of annuities and programmed withdrawal for different distributions of preferences for financial instruments. Given a distribution of preferences, we can map these utilities to a model of market equilibrium by calculating annuity demand and average cost. Additionally, we can alter the rules governing how individuals access their retirement savings, recalulate utilities, and study how the annuity market equilibrium changes.

Below, we focus on a 60 year old female, retiring in 2007 with relatively high pension savings. ${ }^{25}$ We model heterogeneity in mortality risk as normally distributed shifts over the mortality tables used by the Chilean pension authorities ${ }^{26}$. More precisely, given a retiree's age, these tables give us a mortality probability vector. We introduce heterogeneity as shifts in the individuals' age, so that a 65 year old retiree with a $x$ year mortality shifter has the mortality probability vector

\footnotetext{
${ }^{25}$ At the third quartile of pension savings for women in our data

${ }^{26}$ Superintendencia de Pensiones and Superintendencia de Valores y Seguros
} 
of a $65+x$ year old. This allows us to introduce unobserved heterogeneity in mortality risk in a parsimonious way, at the cost of assuming that all shifts in mortality preserve the shape of the regulatory agencies' tables ${ }^{27}$.

In the baseline case, all other parameters in the model will be held fixed, so that the only source of unobserved heterogeneity is mortality. Parameters of the utility function are taken from previous literature when possible. ${ }^{28}$ The risk aversion parameter is 3, interest rate is $3.18 \%$ (yearly), the mean and standard deviation of the mortality shifter are 0 and 10, the bequest motive parameter is 1 , and $20 \%$ of the retiree's total wealth that is in pension savings. ${ }^{29}$ To illustrate how correlation across dimensions of unobserved heterogeneity can affect annuity market equilibria, we will also present results where we keep the previous means but add positive correlation between the mortality shifter and bequest motive, and negative correlation between this shifter and both outside wealth and risk aversion.

We model retirees as choosing to allocate their pensions savings dollar-for-dollar between programmed withdrawal and a simple annuity with no deferral or guarantee period. We are abstracting away from heterogeneity in preferences for contracts and preferences for firms, in order to focus on how the demand function changes across institutional regimes.

To calculate the annuity demand function, we take a grid over the space of yearly annuity payouts (expressed as a percentage of the pension balance) and calculate, for every type and payout combination, the optimal allocation of pension balance between the annuity and programmed withdrawal. This yields a vector of fractions of wealth annuitized for each level of annuity payout. To obtain the aggregate fraction of wealth annuitized, or quantity demanded, we integrate over the distribution of mortality shifters. To obtain the average cost of the annuitant population, we first

\footnotetext{
${ }^{27}$ These tables are specifically designed to capture the mortality expectations of the retiring population.

${ }^{28}$ Our parameters for risk aversion, interest rates, bequests and outside wealth match or lie in the range discussed by Hosseini (2015), as well as Einav, Finkelstein and Schrimpf (2010) and Lockwood (2012).

${ }^{29}$ Wealth in the pension system is 3040 UFs, and outside wealth is 12160 UFs
} 


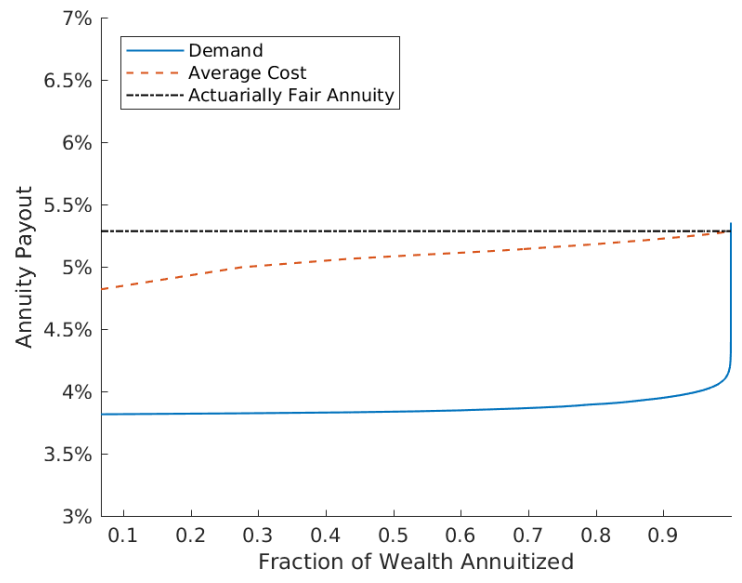

(a) Heterogeneity in mortality only

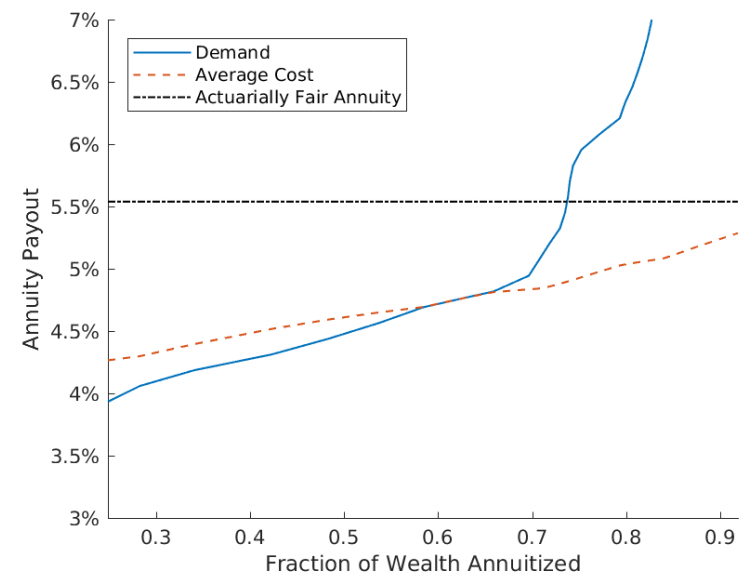

(b) Full heterogeneity

Figure 5: Calibrated annuity demand and average cost curves under baseline institutions

calculate the expected cost of providing a one dollar annuity to each mortality type. Then for each value of total fraction of wealth annuitized we calculate average cost by integrating over the typelevel vector of fractions of wealth annuitized that generated the aggregate quantity. This quantity can also be interpreted as the breakeven annuity offer given the annuitant pool.

The results from this exercise are plotted in figure 5. The left panel reports the case where the only source of heterogeneity is mortality, while the right panel adds in correlation across dimensions of unobservables. In both plots, the $x$ axis is the fraction of wealth annuitized, and the $y$ axis shows the value of the unit annuity payout. Note that demand is upward sloping on these axes, as higher pension payouts lead to larger fractions of wealth annuitized.

The intersection of the average cost curve and demand describes the market equilibrium under perfect competition. In figure 5a, we see that in the case where the only source of heterogeneity is mortality, the equilibrium features full annuitization at the actuarially fair payout. Figure $5 \mathrm{~b}$, on the other hand, presents an equilibrium with an annuitization rate of around $65 \%$ and an equilibrium price significantly below the actuarially fair amount. This is to be expected - the annuitization puzzle literature has established that non-mortality dimensions of preference for annuitization can 


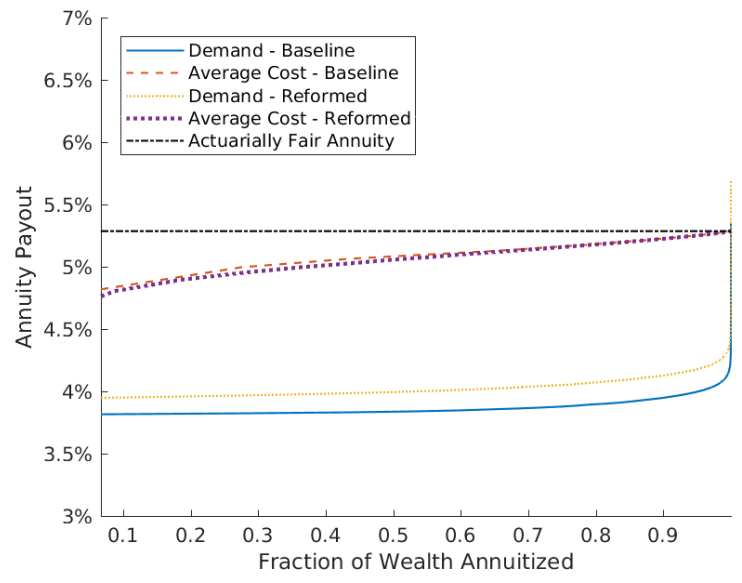

(a) Heterogeneity in mortality only

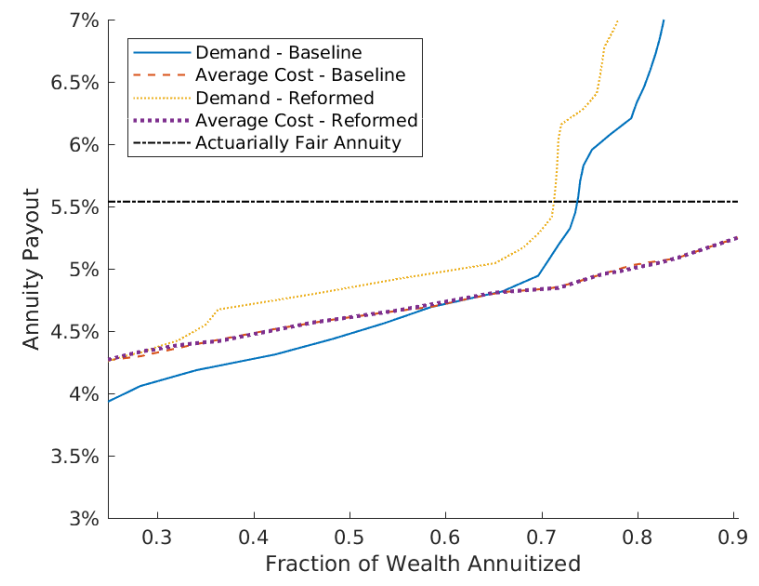

(b) Full heterogeneity

Figure 6: Calibrated annuity demand and average cost curves under reformed institutions

lead to equilibria with less than full annuitization (for example, Lockwood (2012)).

Let us now consider the effects of imposing annuitization of a fraction of pension savings and of allowing for lump sum withdrawal of the remainder. We follow Mitchell et al. (1999)) and impose annuitization of one half of pension balances, only allowing retirees to decide the allocation of the remaining half to either a lump-sum withdrawal or to a private market annuity. Figure 6 presents the results of the same supply-and-demand analysis as before for both this reformed setting and the baseline case. In the case where the only source of heterogeneity is mortality expectations (figure 6a), we see that reforming the system has no effect on equilibrium prices and quantities. That is, while this change in the rules governing how individuals can access their funds contracts the annuity demand curve, this contraction is not enough to lead to an equilibrium with less than full annuitization. However, in the case with correlation across dimensions of unobserved type, we see that the reform drops the annuitization rate to $30 \%$. That is, holding primitives fixed, introducing mandatory annuitization and the potential for lump-sum withdrawal partially crowdsout the private annuity market.

There are three main forces leading to these results. First, there is a contraction and rotation 
of the demand curve that comes directly from the fact that $50 \%$ of wealth is already annuitized. In other words, every type requires a higher payout to annuitize the marginal dollar when $50 \%$ of wealth is pre-annuitized than when no wealth is, and the magnitude of this effect is heterogenous across types. Second, there is a further contraction and rotation that comes from the fact that lump sum withdrawals weakly dominate programmed withdrawal, as the former has identical bequest and risk properties than the latter but does not constrain the path of consumption over time. Finally, the reform reorders the relative willingness-to-accept of the different types, changing the annuitant population for any level of wealth annuitized. As a result, the average cost curve changes. ${ }^{30}$ However, in these calibrations this effect is minor.

These calibrations shows that Chile's exception to the annuity puzzle could be driven in part by the design of the retirement system, relative to other settings where retirees have a fraction of their wealth already pre-annuitized. However, whether this is the case or not depends on the relationship between expected mortality and other dimensions of unobserved preferences for annuitization. This implies that in order to estimate the differential level of selection in Chile and its contribution to the high annuitization rate, we need to specify a model of demand and cost that can flexibly account for these correlations. Moreover, as shown above, we cannot rely on linear approximations to the demand and cost curves. Such an approach would not capture how a large counterfactual reform can shift the shape of the average cost and demand curves, or introduce non-monotonicities. In the following sections, we proceed to flexibly estimate the underlying distribution of private information that drives both demand and cost curves. This will allow us both to simulate the counterfactual equilibrium and to perform welfare comparisons across regimes.

\footnotetext{
${ }^{30}$ This happens in figure 6 a even though the only source of heterogeneity is mortality, as for each offer generosity the relative fractions of wealth annuitized across types will change.
} 


\section{Estimation}

In this section we embed the numerical solutions to the model introduced in Section 3 into a demand estimation framework to recover distributions of unobserved preferences. We then use these estimates in Section 6 to study the impact of different features of the Chilean retirement exchange on equilibrium outcomes.

\subsection{Framework}

In the previous section, we showed how to obtain the value of any offer in the system given contract characteristics, individual observables such as age and gender, and individual unobservables such as initial wealth, risk aversion, bequest motive and mortality and bankruptcy beliefs. Denote the set of individual-offer-firm observables that enter into the optimal consumption-savings problem when faced with an annuity offer as $X_{i o j}^{A}$, the analogous individual-firm set for a PW offer as $X^{P} W_{i j}$, and individual $i$ 's combination of unobservables - a "type" - as $\theta_{i}$. We can then denote the value of an annuity offer $o$ that firm $j$ makes to individual $i$ by $V^{A}\left(X_{i o j}^{A}, \theta_{i}\right)$, and the value of taking programmed withdrawal from PFA $j$ as $V^{P W}\left(X_{i j}^{P W}, \theta_{i}\right)$.

More specifically, age and gender are individual observables that affect the utility calculation for both annuities and PW, as individuals retire at different ages and there are significant mortality differences across genders. For annuities, the payment amount, deferral and guarantee periods, and payments upon bankruptcy $\rho_{o j}$ also enter into the problem; we match firm risk ratings to Fitch Ratings' 10 year Average Cumulative Default Rates for Financial Institutions in Emerging Markets for 1990-2011 and use these rates as bankruptcy probability beliefs. For PW offers, individuals need to take into account the fee. As for types, the following unobservables enter the problem: risk aversion $\gamma_{i}$, outside wealth $\omega_{i}$, bequest motive $\beta_{i}$, and mortality probability vector $\mu_{i}$. We will 
denote the joint distribution of these unobservables as $F(\theta)$.

We then recover the joint distribution $F(\theta)$ using the estimator developed by Fox et al. (2011) and Fox, il Kim and Yang (2016). First, we discretize the space of types and solve the optimal consumption-savings problem for every individual-offer-type combination. Then, we assume that each individual-type combination selects the highest utility offer available to them, and solve for the joint distribution of types that rationalizes observed choices. To be more specific, denoting a point in this grid by $r$, we impose that the probability a individual $i$ accepts offer $o$ from firm $j$ if they are of type $r$ when faced with the set of annuity offers $\mathscr{O}_{i}^{A}$ and the set of PW offers $\mathscr{O}_{i}^{P W}$ is

$$
s_{i o j r}=\left\{\begin{array}{l}
1 \text { if } V^{A}\left(X_{i o j}^{A}, \theta_{r}\right) \geq \max \left[\max _{o^{\prime}, j^{\prime} \in \mathscr{O}_{i}^{A}} V^{A}\left(X_{i o^{\prime} j^{\prime}}^{A}, \theta_{r}\right), \max _{j^{\prime} \in \mathscr{O}_{i}^{P W}} V^{P W}\left(X_{i j^{\prime}}^{P W}, \theta_{r}\right)\right] \\
0 \text { otherwise }
\end{array}\right.
$$

We estimate the type probabilities that rationalize observed choices using constrained OLS:

$$
\begin{aligned}
& \min _{\pi} \sum_{i, o, j}\left(y_{i o j}-\sum_{r} s_{i o j r} \pi_{r}\right)^{2} \\
& \text { subject to: } \\
& \pi_{r} \geq 0 \forall r \\
& \sum_{r} \pi_{r}=1
\end{aligned}
$$

where $y_{i o j}=1$ if individual $i$ accepts offer $o$ from firm $j$ and 0 otherwise.

The main benefit of this approach is that after recovering the joint distribution of types, one can solve the optimal consumption-savings problem for assets that are out of sample and predict choice probabilities and selection into assets. The two main concerns are the choice of grid, an issue we will discuss in detail below, and the assumption that each type accepts the offer that maximizes the 
value obtained from the consumption-savings problem. This implies that, conditional on a contract type, the only source of heterogeneity across firms beyond the amount they offer is their bankruptcy probability: there can be no non-financial utility components. Thus, the model cannot rationalize the acceptance of dominated offers. While $19 \%$ of accepted annuity contracts are dominated, the small monetary amounts lost when accepting a dominated offer - around $1 \%$ of the offered amount - leave us unconcerned by this feature of the model.

Another implication of this assumption is that we are also assuming away the standard endogeneity concern in demand estimation by ruling out non-financial utility terms that can be priced into contracts. Again, since the main variation in contract values comes from the contract terms, and not from variation in offered amounts, we do not think that this assumption is too restrictive. Furthermore, our counterfactuals of interest analyze cases where there is a perfectly competitive annuity market, and thus do not require the identification of tastes for firms.

Finally, one could be concerned about information revelation in the request stage - if individuals with different expected costs request different contracts, then firms should price based on the request phase, creating correlation between the observed offers and the unobserved types. To check whether this concern is empirically relevant, we take the most commonly requested contract - a "0-0" contract with no guarantee and no deferral period, which is requested by more than $90 \%$ of retirees - and study whether offer generosity varies as a function of whether the retiree also requests a contract with a guarantee period or a contract with a deferral period. If there was information revelation in the request stage, then requesting a deferral period would reveal that the individual expects to be long-lived, lowering the generosity of the "0-0" contract. On the converse, requesting a guarantee period contract would reveal that the individual expects to have a non-trivial probability of dying within the guarantee period, and that they care about leaving money to their heirs. Such a person should be cheaper to serve and should value programmed withdrawal more than the average retiree, so we would expect " $0-0$ " contracts to be more generous. To implement 
this test, we regress offered amounts on three request dummies - request a deferral period contract, request a guarantee period contract, and the interaction - while controlling flexibly for pension balances and the full interaction of retirement month-year, age and gender fixed effects. Results from this exercise are in table 18 in Appendix . Overall, we do not find economically significant information revelation effects. For example, column 1 implies that requesting a deferral period decreases offer generosity by $0.5 \%$, requesting a guarantee period decreases offer generosity by $0.4 \%$, and requesting both has no effect.

\subsection{Implementation}

The goal of the estimation procedure is to recover the joint distribution of unobserved preferences without specifying restrictive functional form assumptions.

First, we pick a grid over the space of $\pi$. Recall that $F(\pi)$ is the joint distribution of risk aversion $\gamma$, initial wealth $\omega$, bequest motive $\beta$ and mortality probability vector $\mu$. These objects must be further restricted, as creating a grid over this space is computationally infeasible ( $\mu$ alone is a $T \times 1$ object). To do so, we model the mortality probability vector $\mu$ as the mortality vector from the Chilean mortality tables in place at the time of retirement plus an unobserved shifter that makes retirees an arbitrary number of years younger or older than their retirement age. For example, an individual who retires at 60 with a mortality shifter value of 2 solves the optimal consumption-savings problem for each contract using the mortality vector of a 62 year old. This allows the model to continue to feature adverse selection into contracts, as individuals with low (high) mortality shifter draws are unobservably younger (older) than their age, without having to separately identify whether this selection comes from a higher death probability in year $x$ or $x+1$.

This resulting type space has only four dimensions: risk aversion, initial wealth, bequest mo-

tive, and mortality shifter. We solve the optimal consumption-savings problem for every individual- 
firm-annuity offer, imposing $\delta=0.95$, and $R=1.03$. For programmed withdrawal, since PW fees are almost identical across PFAs and we are not interested in modelling substitution across them, we solve the optimal consumption-savings problem for one PW offer, assuming the fee is the median fee. Furthermore, we assume that the PW problem is non-stochastic, and set the mean PW return to its empirical counterpart.

Now we select a grid over type space. The main challenge here is to construct a grid that is rich enough to span the support of the distribution of unobservables and to distinguish between regions of type space with significantly different preferences over the counterfactuals of interest, but that is small enough to be implementable - we must solve the optimal consumption-savings problem for each observed offer in our data and for every grid point. Instead of selecting the grid arbitrarily, we incorporate a model selection step that essentially starts with an extremely large grid and coarsens it as a function of predicted decisions in our counterfactuals of interest and in a subsample of our data. We then use this selected grid in our full sample. See Appendix B for a description of this process and for robustness checks. Through this step we are able to start with a grid that plausibly spans the support of the distribution of types, but that is infeasible to take to the data, and reduce its dimensionality without significantly limiting the outcomes that the model can cover or the predictions that will later be made in the counterfactuals of interest.

\subsection{Identification}

How is the distribution of types identified? Following Fox, il Kim and Yang (2016), one can think of our model as estimating the parameter distribution $F(\beta)$ in the model

$$
P_{j}(x)=\int g_{j}(x, \beta) d F(\beta)
$$


where $j$ is the index of the $j$ th value in the choice set, $P_{j}(x)$ is the probability that offer $j$ is chosen given observables $x$, and $g_{j}(x, \beta)$ is the modelled probability that offer $j$ is chosen given $x$ and $\beta$. The observables that enter into the model are age, pension balance, and the set of offers received. In our setting, the consumption-savings model generates utilities for each individual, offer and type, and so $g_{j}(x, \beta)=1$ if for a given individual and $\beta$ offer $j$ is the highest utility offer.

Since $g_{j}(x, \beta)=1$ is known, we are concerned with identification of the distribution of types $F(\beta)$. And because we are concerned with identifying distributions of types conditional on gender and pension balance quartile, the variation in observables that yields identification occurs within these bins. In this setting, there are several sources of variation that rule out observational equivalence across distributions. First, selection into contracts conditional on $x$. Since the financial value of an annuity contract is greatly dependent on the match between the contracts' terms and the preferences of the annuitant, types will have different rankings across offers. For example, as the number of guarantee periods increases, annuity payouts always decrease. This implies that individuals with no bequest motive will always prefer contracts without guarantee periods, while as bequest motive increases retirees will value contracts with longer guarantee periods more. As another example, contracts with deferral years imply a tradeoff between higher annuity payouts until death and an initial period of time without any annuity income. Only individuals who expect to live long enough to recoup this investment and who have sufficient assets outside the system to fund the initial periods will find these offers attractive. Therefore, even conditional on $x$, two distributions that place different mass on different regions of type space will predict different choice probabilities across contract types.

A second source of variation stems from the fact that firms bid at the individual-contract level, so each retiree receives different bids for the same firm-contract. One important driver of this variation is within firm, cross time changes in hedging costs, which can be thought of as cost-side variation. Another source of variation are differences across individuals in observables such as 
age and pension balance (within gender and balance quartile). Finally, a third source of variation is that the set of contracts individuals can choose from varies across retirees. This happens both for technical reasons (only eligible retirees can receive free disposal and transitory rent offers), for cost-side reasons (firms choosing not to bid on low balance individuals), and because retirees request different contracts in the initial stage.

There are two concerns with these arguments. The first is the assumption that there is no nonfinancial utility in the observed offers. If that is not the case, then firms may price on these nonfinancial terms, creating dependence between the observed offer characteristics and the error term. We believe that the empirical relevance of this concern is minor, as the amount of money lost when an individual accepts a dominated offer (one that can only be rationalized by non-financial utility) is small. The second is that the observed variation in offers across individuals is correlated with the distribution of types, by firms screening on observables. This is the reason why we estimate type distributions separately by gender and by quartiles of pension balance. The remaining observables transmitted to firms before they formulate their offers are age, which is controlled for flexibly in the model, number of legal beneficiaries, for which there is no variation in our subsample, and contracts types requested, which we have already shown to have no effect on offer generosity.

\section{Results}

This section presents demand estimation results, measures of in and out of sample fit, and uses the estimated model to unpack how reforming the pension regime affects annuity market equilibria and retiree welfare. 


\begin{tabular}{|c|c|c|c|c|c|c|}
\hline \multicolumn{7}{|c|}{ Panel A: CDF Summary } \\
\hline \multicolumn{3}{|c|}{ Mass Cutoff } & $1.00 \mathrm{E}-01$ & $1.00 \mathrm{E}-02$ & $1.00 \mathrm{E}-03$ & $1.00 \mathrm{E}-04$ \\
\hline \multirow{2}{*}{\multicolumn{3}{|c|}{$\begin{array}{c}\text { Number of Points with Mass Greater than Cutoff } \\
\text { Total Mass for these Points }\end{array}$}} & 1 & 26 & 48 & 50 \\
\hline & & & $21.58 \%$ & $89.26 \%$ & $99.87 \%$ & $100.00 \%$ \\
\hline \multicolumn{7}{|c|}{ Panel B: Top 10 Mass Points } \\
\hline & Bequest Motive & Risk Aversion & Outside Wealth & Health Shifter & Mass & $95 \% \mathrm{CI}$ \\
\hline 1 & 621 & 0.000 & 10.100 & 15 & $21.58 \%$ & $(20.02 \%, 23.14 \%)$ \\
\hline 2 & $7.89 \mathrm{E}+03$ & 5.000 & 0.200 & -1 & $7.57 \%$ & $(6.33 \%, 8.81 \%)$ \\
\hline 3 & 0.414 & 0.000 & 0.200 & 15 & $6.16 \%$ & $(5.23 \%, 7.09 \%)$ \\
\hline 4 & 137 & 1.875 & 0.200 & -15 & $4.26 \%$ & $(3.10 \%, 5.42 \%)$ \\
\hline 5 & $7.89 \mathrm{E}+03$ & 4.375 & 0.200 & -1 & $4.11 \%$ & $(2.82 \%, 5.40 \%)$ \\
\hline 6 & 0.000289 & 0.625 & 16.288 & 15 & $3.86 \%$ & $(2.83 \%, 4.90 \%)$ \\
\hline 7 & 44.6 & 0.625 & 18.762 & -3 & $3.49 \%$ & $(2.07 \%, 4.92 \%)$ \\
\hline 8 & 17.5 & 0.000 & 8.862 & -1 & $2.66 \%$ & $(2.30 \%, 3.03 \%)$ \\
\hline 9 & 3.59 & 0.000 & 11.338 & -1 & $2.66 \%$ & $(2.30 \%, 3.03 \%)$ \\
\hline 10 & 44.6 & 1.875 & 0.200 & -3 & $2.65 \%$ & $(1.14 \%, 4.16 \%)$ \\
\hline
\end{tabular}

Notes: Panel A reports the number of points whose estimated mass is above different values and the total mass for those points. Panel B reports the ten points with the highest estimated masses, as well as their estimated weights and $95 \%$ confidence regions. These confidence intervals are calculated using clustered standard errors at the individual level.

Table 3: Descriptive Statistics for Estimated Type Distribution - Third Quartile Females

\subsection{Estimates}

As described in the previous section, we estimate the model separately for each combination of gender and pension balance quartile. For clarity and brevity, we present results for women in the third pension balance quartile here, and report results for all other female balance quartiles in Appendix C. Results for males are available upon request. We focus on this subgroup as our sample is predominantly female, and their relatively higher levels of pension savings (between US $\$ 88,000$ and US\$135,000) make them more comparable to other settings. Table 3 presents the 10 grid points with highest estimated mass for this subsample, while figure 7 presents marginal distributions for each dimension of unobserved type. We report standard errors that are clustered at the individual level. ${ }^{31}$

The estimated type distribution is disperse, with only one point with mass greater than 10\%, 26

\footnotetext{
${ }^{31}$ These standard errors are conservative, as they do not take into account that the true parameter cannot be negative - see Fox et al. (2011).
} 

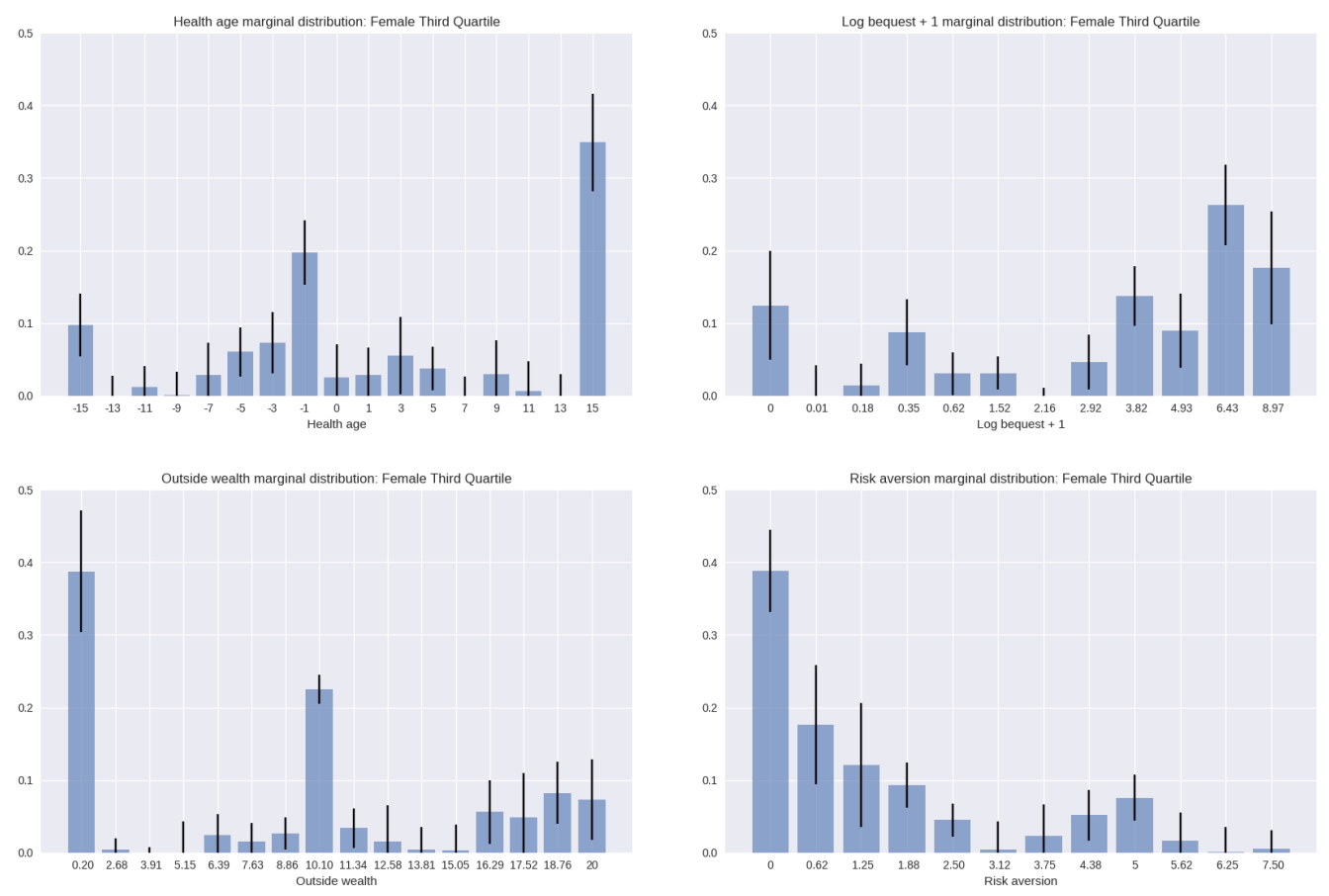

Figure 7: Marginal Distributions - Females in the Third Quartile of Pension Savings

points with mass greater than $1 \%$, and 48 points with mass greater than $0.1 \%$. Considering only the 50 points with mass greater than $0.01 \%$ results in almost perfect coverage (99.9997\%) of the full type distribution. The distribution of the health age shifter ${ }^{32}$ exhibits substantial heterogeneity, with $50.5 \%$ of retirees exhibiting higher death probabilities than those in the Chilean authorities' table. In particular, there is large mass assigned to the health shifter value of 15 . For a 60 year old woman, a mortality shifter value of 15 corresponds to a life expectancy of approximately 75 years.

As for bequest motives, around $12 \%$ of retirees in this group behave as if they assign no value to leaving money to their heirs, but there is also significant mass at the largest values of the grid. This heterogeneity in bequest motive, and its correlation with mortality, plays an important role in equilibrium outcomes and in counterfactuals, as individuals with high bequest motives value annuitization less, even if it comes at an actuarially fair price. In particular, a mandatory annuitization

\footnotetext{
${ }^{32}$ Recall that an individual who retires at age $x$ with a health shifter of $y$ solves the optimal consumption-savings problem with the mortality expectations of an $x+y$ year old according to the Chilean mortality tables.
} 
policy is likely to significantly decrease the utility of this population as well as greatly reduce their demand for annuities. We will return to this issue below.

The distribution of outside wealth has a large mass point at the lowest value in the grid (US\$ 8,170), consistent with survey evidence (Comisión Asesora Presidencial Sobre el Sistema de Pensiones (2015)) that for many retirees pension savings are their lone asset for funding consumption after retirement. Despite this, there is also substantial mass at the highest points in the grid. We believe this is reasonable, considering that this object is meant to capture the value of all assets that can fund consumption and inheritance, and that our sample is restricted to individuals who can fund an annuity offer above the minimum pension.

Finally, the marginal distribution of risk aversion has large mass at $\gamma=0$, which corresponds to risk neutrality, and most mass below $\gamma=3$. The mean of the distribution of $\gamma$ is 1.39 .

\subsection{Correlations}

In this setting, marginal distributions do not tell the whole story, as the relationship between the unobservables will greatly affect choices and equilibrium outcomes. In particular, if individuals with low mortality expectations also have high preferences for annuities due to other unobserved characteristics, then the annuity market can feature advantageous, not adverse, selection. A nice feature of our estimation procedure is that we are non-parametrically estimating the joint distribution of unobserved types, allowing us to flexibly determine the relationship between these unobservables. Table 4 presents these correlations for females in the third quartile of pension balances. Other groups are reported in Appendix C.

The strongest correlations correspond to risk aversion and bequest motive (0.76), risk aversion and outside wealth (-0.56), and risk aversion and the health shifter (-0.52). The first correlation 


\begin{tabular}{ccccc}
\hline \hline & Bequest Motive & Risk Aversion & Outside Wealth & Health Shifter \\
\hline Bequest Motive & 1.00 & 0.76 & -0.34 & -0.22 \\
Risk Aversion & 0.76 & 1.00 & -0.56 & -0.52 \\
Outside Wealth & -0.34 & -0.56 & 1.00 & 0.24 \\
Health Shifter & -0.22 & -0.52 & 0.24 & 1.00 \\
\hline
\end{tabular}

Table 4: Correlations Across Dimensions of Unobserved Type - Third Quartile Females

is likely to be reflective of the choice of annuities with a guarantee period, as such a contract is valuable to individuals who highly penalize both outliving their funds (or they would not annuitize) and leaving no money to heirs (or they would not choose a guarantee period). The second correlation is intuitive, as higher outside wealth means that individuals can self-insure. Finally, a negative correlation between risk aversion and the health shifter implies that risk averse individuals have longer life expectancies, perhaps due to a lower propensity to smoke and engage in risky behaviors, and their higher consumption of preventative healthcare (Anderson and Mellor (2008)) ${ }^{33}$. There is also negative correlation between outside wealth and bequest motive, perhaps due to the fact that richer retirees also have richer heirs, as one would expect in a country with low (albeit improving) intergenerational mobility of income (Torche (2005), Sapelli (2016)).

Focusing on the health shifter, we find a negative correlation between this unobservable and bequest motives, and a positive correlation with outside wealth. To illustrate the effects of these correlations on annuity demand, we calculate the fraction of wealth each type would annuitize if given a choice between an actuarially fair annuity and programmed withdrawal, and integrate out over all dimensions of unobserved type except for mortality shifter. Figure 8 presents a scatter plot of the value of the mortality shifter and the average fraction of wealth annuitized for that shifter value. Naturally, higher values of the mortality shifter correspond to lower annuitization rates, as these individuals are shorter lived. As a result, it is not surprising that the best fit line across these

\footnotetext{
${ }^{33}$ Our analysis abstracts away from moral hazard, meaning that we assume the choice to annuitize and to purchase a particular contract type does not determine life expectancy. We do not think that this assumption is restrictive, given that net NPVs for these contracts are not too dissimilar.
} 
points is decreasing. However, the scatter plot shows substantial non-monotonicity in the relationship between health shifter and fraction annuitized. This highlights that the correlation across dimensions of unobservables plays a significant role in determining equilibrium outcomes. In a setting where mortality realizations are independent of all other dimensions of type, willingness to pay for an annuity (conditional on gender, age and pension balances) solely depends on these expectations. ${ }^{34}$ As a result, the first annuitized dollars in this market will correspond to individuals who expect to be long lived. If these expectations are correct, this will induce adverse selection. However, if other dimensions of unobserved type are correlated with mortality, this result can be overturned. For example, our demand estimates imply that higher bequest motives are associated with longer life expectancies. As a result, long lived individuals have less of an incentive to annuitize than predicted under the assumption of independence across types. This pushes the annuity market towards advantageous selection. As a counterexample, a negative correlation between risk aversion and health shifter - or positive correlation between risk aversion and life expectancy implies that the individuals who have the greater disutility of outliving their money are also the most expensive to annuitize. We return to the issue of advantageous versus adverse selection into annuitization below.

\subsection{Model Fit and Equilibrium}

Before discussing these issues, Table 5 presents various measures of in-sample and out-ofsample fit of the demand estimation model, by gender-pension balance quartile. The model does a reasonable job fitting the observed choices, despite ruling out any non-financial value of an annuity offer. This is particularly true for the take-up of any annuity versus programmed withdrawal ("Fraction Annuitized"), and for the fraction of individuals accepting an offer that mixes an annuity with programmed withdrawal ("Fraction in Mixed Annuities"). However, it under-predicts the

\footnotetext{
${ }^{34}$ Which is the relevant conditioning set of variables in Chile, as all of these quantities are observed and priced on
} 


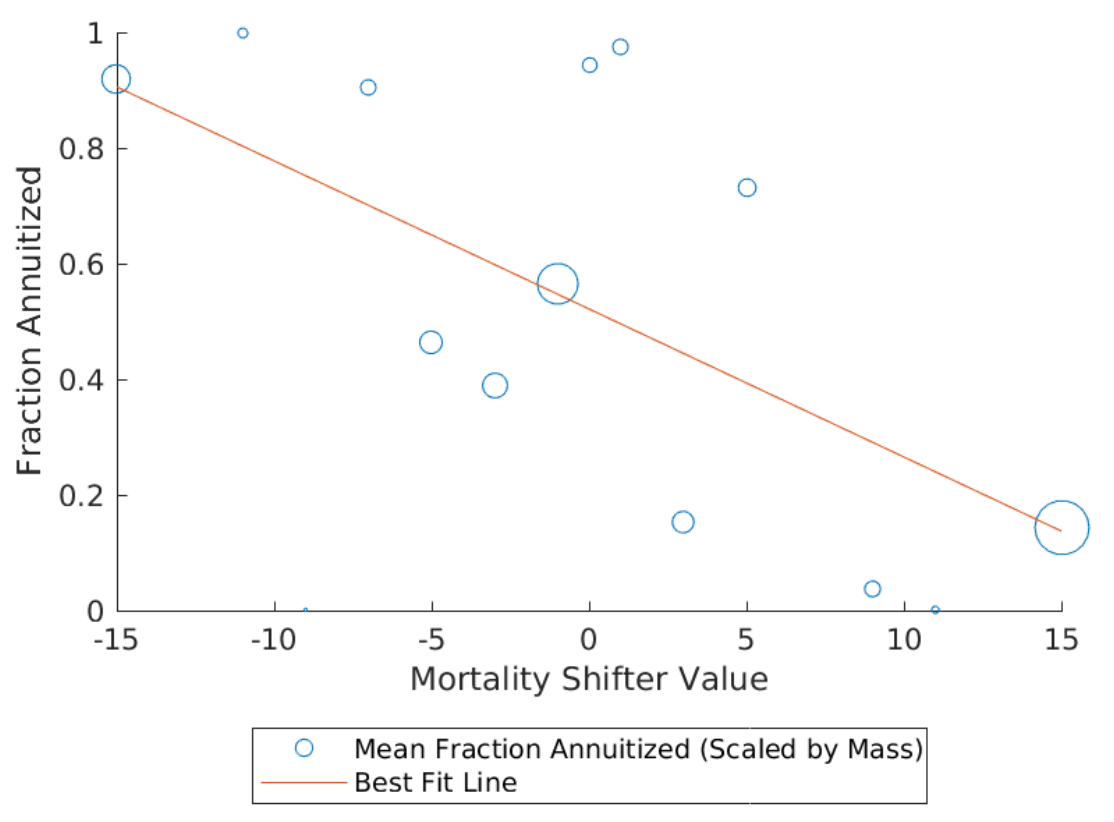

Figure 8: Fraction of wealth annuitized, when choosing between PW and an actuarially fair annuity, as a function of the mortality shifter

fraction of individuals who take a deferred annuity and the fraction of individuals who take a guaranteed annuity. The bulk of this under-prediction stems from the fact that the model has difficulty rationalizing acceptances of annuities with both a deferral period and a guarantee period. Deferral periods are only valued by individuals who expect to be long-lived enough to recoup the "investment" of not receiving payoffs for a few years, while guarantee periods are only attractive to agents with a significant bequest motive who have a non-trivial probability of death before the guarantee period expires. ${ }^{35}$ This under-prediction is therefore to be expected from our model. Nevertheless, we are reassured by the fact that the model fits the (out-of-sample) two-year mortality well, which suggests that we are in fact recovering reasonable estimates of the distribution of unobserved types from our model.

We now turn to the analysis of the annuity market equilibrium. Our goal is to analyze the im-

\footnotetext{
${ }^{35}$ We suspect that adding behavioral types, such as loss-averse retirees, could address this issue (Shu, Zeithammer and Payne (2016)).
} 


\begin{tabular}{|c|c|c|c|c|}
\hline Wealth Quartile & First & Second & Third & Fourth \\
\hline \multicolumn{5}{|l|}{ Fraction Annuitized } \\
\hline Observed & $66.89 \%$ & $76.60 \%$ & $75.30 \%$ & $65.80 \%$ \\
\hline Predicted & $58.77 \%$ & $70.37 \%$ & $71.53 \%$ & $64.40 \%$ \\
\hline \multicolumn{5}{|c|}{ Fraction in Mixed Annuities } \\
\hline Observed & $5.64 \%$ & $7.93 \%$ & $9.54 \%$ & $6.26 \%$ \\
\hline Predicted & $4.24 \%$ & $5.16 \%$ & $6.66 \%$ & $5.14 \%$ \\
\hline \multicolumn{5}{|c|}{ Fraction in Deferred, Non-Guaranteed Annuities } \\
\hline Observed & $3.07 \%$ & $3.53 \%$ & $3.77 \%$ & $3.51 \%$ \\
\hline Predicted & $4.52 \%$ & $7.49 \%$ & $8.07 \%$ & $6.58 \%$ \\
\hline \multicolumn{5}{|c|}{ Fraction in Deferred \& Guaranteed Annuities } \\
\hline Observed & $17.16 \%$ & $29.79 \%$ & $33.05 \%$ & $23.11 \%$ \\
\hline Predicted & $4.76 \%$ & $11.19 \%$ & $14.16 \%$ & $10.22 \%$ \\
\hline \multicolumn{5}{|c|}{ Fraction in Guaranteed, Non-Deferred Annuities } \\
\hline Observed & $37.08 \%$ & $35.12 \%$ & $30.61 \%$ & $29.79 \%$ \\
\hline Predicted & $31.36 \%$ & $34.49 \%$ & $33.64 \%$ & $32.10 \%$ \\
\hline \multicolumn{5}{|l|}{ Two-Year Mortality } \\
\hline Observed & $1.87 \%$ & $1.71 \%$ & $1.69 \%$ & $1.94 \%$ \\
\hline Predicted & $1.55 \%$ & $1.71 \%$ & $1.39 \%$ & $1.23 \%$ \\
\hline Number of Offers & 227332 & 366987 & 593671 & 428247 \\
\hline Number of Individuals & 8433 & 8409 & 10697 & 6585 \\
\hline MSE & 0.03 & 0.02 & 0.02 & 0.01 \\
\hline$R^{2}$ & 0.30 & 0.23 & 0.22 & 0.26 \\
\hline
\end{tabular}

Table 5: Measures of In-Sample and Out-of-Sample Fit 


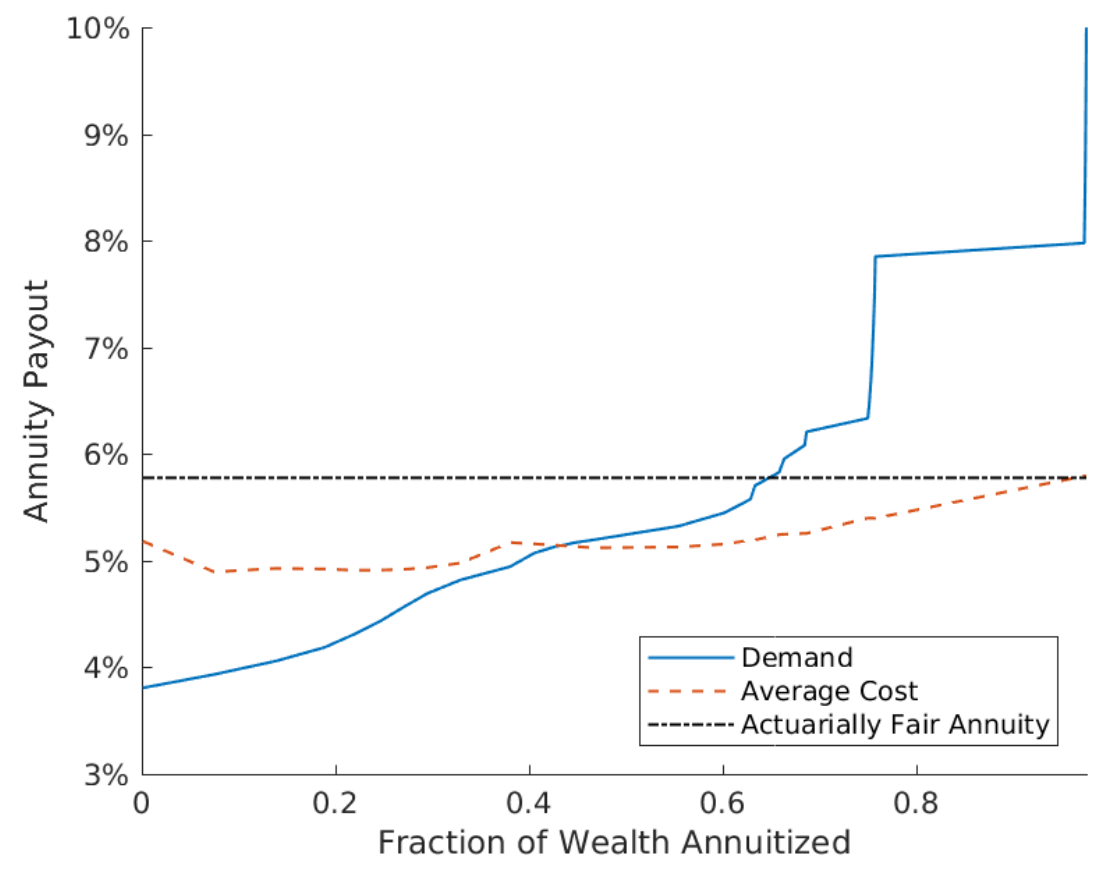

Figure 9: Simulated Equilibrium under Baseline Policy - Third Quartile Females

plied annuity demand and average cost curves in the baseline Chilean setting, and to then study how these functions are affected by changing the institutional setup. To do so, we analyze the equilibrium of a perfectly competitive annuity market where retirees can distribute their pension savings, dollar for dollar, into either an immediate annuity with no guarantee period or programmed withdrawal (with no minimum pension guarantee). Even in this basic setting, incorporating mandatory annuitization and the ability to take lump-sum withdrawal can lead to market unravelling. Note that since age, gender and pension balances can be priced on, every combination of these quantities constitutes a separate market with potentially different equilibria. In what follows, every equilibrium that is presented will be conditional on a combination of these quantities.

Figure 9 presents the implied annuity demand curve and average cost curve for a 60 year old female retiree that retires with a pension balance equal to the third quartile of the distribution of pension balances for females during our sample period. ${ }^{36}$ We construct the annuity demand curve

\footnotetext{
${ }^{36}$ Results for females in other quartiles are similar, and are presented in Appendix C.
} 
by choosing a grid over the space of yearly annuity payouts (expressed as a percentage of the pension balance) and, for every type and payout combination, solving for the optimal allocation of pension balance between PW and an annuity. This gives us the fraction of wealth that each type would annuitize across the grid of annuity payouts. We then aggregate to the market level using the estimated type probabilities, and plot the curve relating annuity payouts to the aggregate fraction of wealth annuitized - the demand curve in this setting. This curve can also be interpreted as a "willingness-to-accept" curve, expressing the worst annuity offer that induces the marginal annuitized dollar. We calculate the average cost curve by calculating the expected cost of a unit annuity for every type, and then using the fraction of wealth each type annuitizes given a price and the type probabilities to obtain the expected cost for the annuitant population at each price. We express this expected cost in the same units as the demand curve, so that it can be interpreted as the break-even annuity offer given the expected cost of the annuitant population. Under adverse selection, this curve is upward-sloping: dollars that are only annuitized after high offers correspond to individuals with higher mortality. Under advantageous selection, on the other hand, the curve is downward sloping. Under our framework, the average cost curve can have regions of advantageous selection and regions of negative selection, depending on the relative mortality expectations of the marginal and inframarginal annuitants.

In figure 9, we find that the equilibrium for third quartile women features an equilibrium annuity offer of $5.14 \%$ of the pension balance per year and $43.3 \%$ of total pension wealth annuitized. The annuity demand curve is non-linear, reflecting the significant heterogeneity in the distribution of types found earlier. Relatedly, the average cost curve is non-monotonic, with regions of adverse and advantageous selection. In particular, we find a region of advantageous selection around the market equilibrium, although globally the average cost curve exhibits adverse selection. Moreover, the impact of adverse selection on the fraction of wealth annuitized is significant: the actuarially fair payout for the whole population is $12 \%$ higher than the equilibrium payout, and at the actuari- 
ally fair amount around 64\% of available funds would be annuitized.

It is important to note that the preceding figures are not a good metric for quantifying the fit of the model, as we have removed several features of the Chilean system in order for these equilibria to be a reasonable benchmark for the counterfactuals that follow. In particular, we are removing the possibility of bankruptcy, the minimum pension guarantee, programmed withdrawal commissions, and multidimensional annuity contract types. These assumptions simplify the problem and allow us to focus on the shifts in demand and average cost induced by changing the rules governing how funds can be accessed.

\subsection{Counterfactual Reforms}

We now consider potential reforms to the current Chilean system. First, we remove the limitations the government places on drawdown, and instead allow retirees to access their full pension savings at retirement. The outside option to purchasing an annuity is free disposal of the entire lump-sum. ${ }^{37}$ The unconstrained option keeps the benefits of PW, including the ability to pass money to heirs and higher liquidity, and adds additional liquidity. That means every type would prefer unconstrained lump-sum withdrawal to programmed withdrawal. Figure 10 shows the impact of redesigning retirement policy in this way on the private annuity market equilibrium for the same third quartile female as in the previous section. The remaining groups are in Appendix C.

This improvement in the outside option shows the same crowding out behavior demonstrated in the calibration. Demand shifts downwards, and average cost changes shape with a local increase in adverse selection near the reformed equilibrium. As a result, the new equilibrium annuity provides a payout of $4.9 \%$ of pension wealth and the equilibrium level of annuitization drops to about 32\%. Comparing the baseline and reformed equilibrium, we can see that the unconstrained lump

\footnotetext{
${ }^{37}$ This option is similar to what is available in Peru, where 95.5\% of funds are available for lump-sum withdrawal.
} 


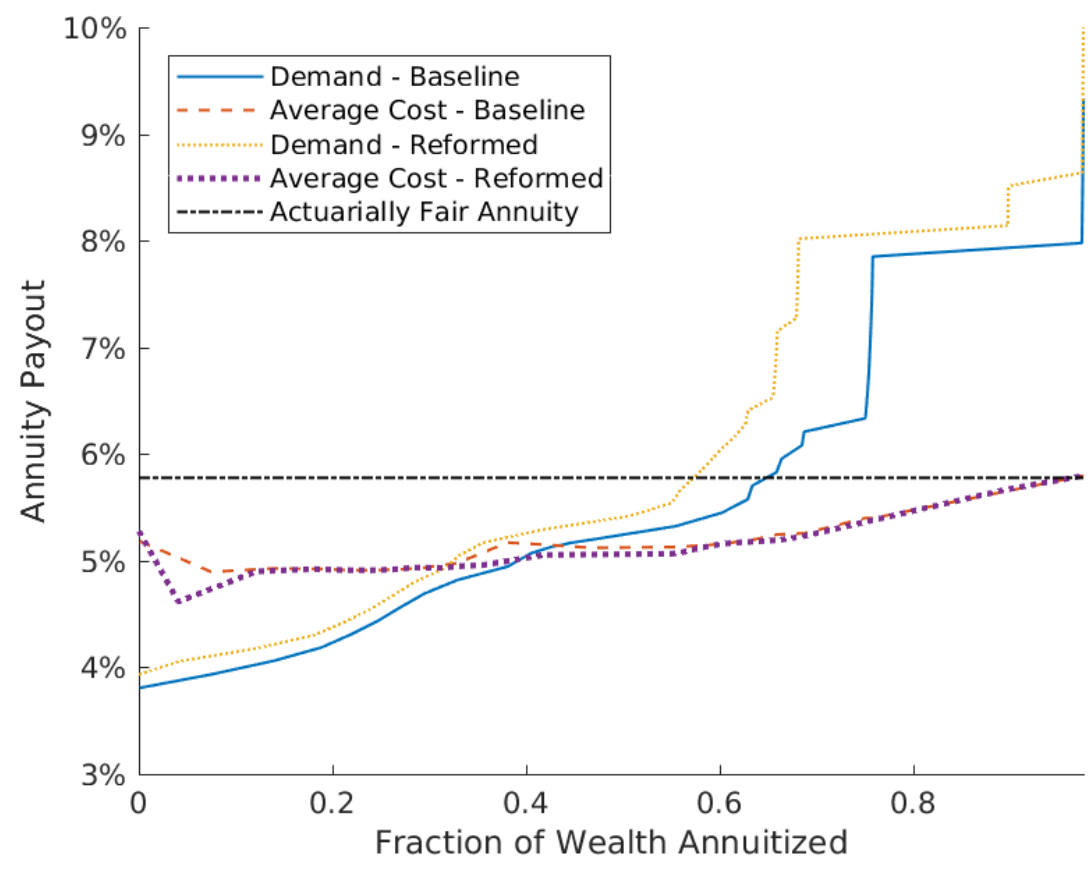

Figure 10: Simulated Equilibrium with Unconstrained Lump-Sum Withdrawal - Third Quartile Females

sum outside option increases the equilibrium price of private annuities and lowers the fraction of pension balances annuitized. The new equilibrium lowers welfare for individuals who would prefer to annuitize all their wealth, since they pay higher prices. That is, improving the value of the outside option does not improve the welfare of all retirees, even though they all prefer the new outside option to the baseline.

We now introduce a retirement policy feature common throughout the developed world: mandatory annuitization of a fraction of pension balances. Following Mitchell et al. (1999), we begin by modeling the public option as a $50 \%$ tax on pension balances that is returned to retirees via an actuarially fair annuity. Retirees then decide to allocate their remaining funds, dollar for dollar, to either a private-market annuity or to a lump-sum withdrawal. Figure 11 presents the results of this exercise.

In this reformed setting, the equilibrium fraction of available wealth annuitized drops to slightly 


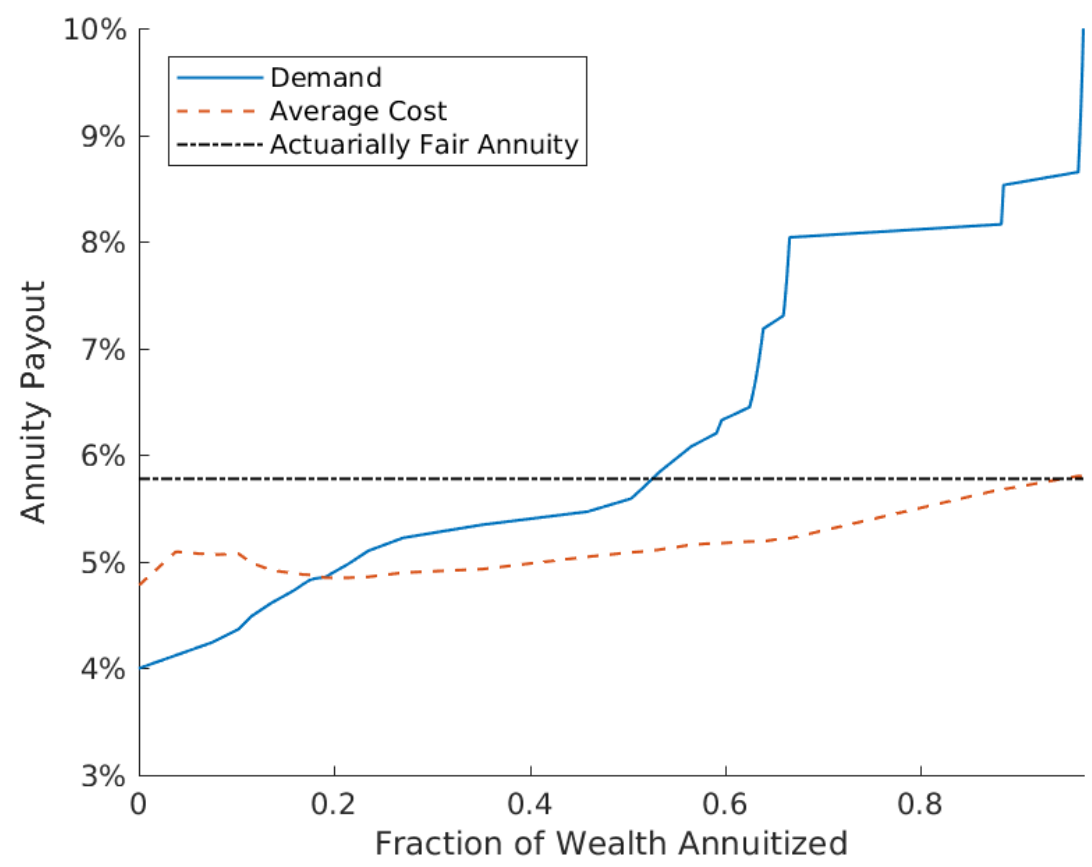

Figure 11: Simulated Equilibrium with 50\% Mandatory Annuitization and Lump-Sum Withdrawal - Third Quartile Females

below $20 \%$, and the equilibrium annuity offer falls to $4.85 \%$. There are three main forces leading to this result. First, there is a contraction and rotation of the demand curve that comes directly from the fact that $50 \%$ of wealth is already annuitized. In other words, every type requires a higher payout to annuitize the marginal dollar when $50 \%$ of wealth is pre-annuitized than when no wealth is, and this effect is heterogenous across types. Second, there is a further contraction and rotation that comes from the fact that lump sum withdrawals dominate programmed withdrawal, as the former has identical bequest and risk properties than the latter but does not constrain the path of consumption over time. Finally, the reform reorders the relative willingness-to-accept of the different types, changing the annuitant population for any level of wealth annuitized. As a result, the average cost curve changes. On net, these three forces reflect how changing the rules governing how individuals can access their retirement funds can have large effects on the private annuity market. 


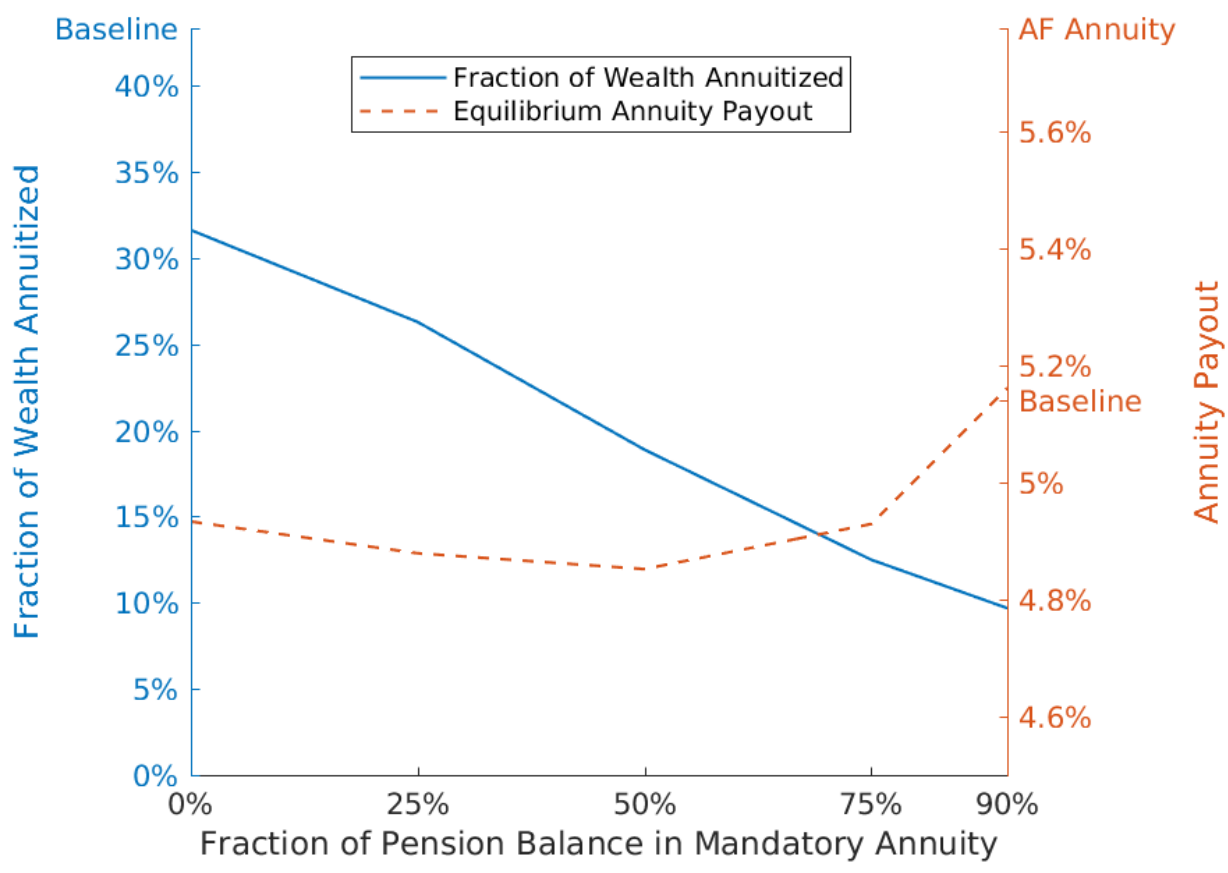

Figure 12: Equilibrium Fractions of Wealth Annuitized and Annuity Payouts as a Function of the Fraction of Wealth in the Mandatory Annuity - Third Quartile Females

We expand the set of counterfactual reforms to include other levels of mandatory annuitization, ranging from $0 \%$ to $90 \%$. That is, we find the equilibrium level of private annuitization, given that retirement policy prescribes that retirees have $\mathrm{x} \%$ of their wealth annuitized at the actuarially fair price, and the remaining $1-x \%$ is free to be allocated between an annuity and a lump sum withdrawal. Figure 12 plots the equilibrium fraction of wealth annuitized (left axis) and the equilibrium annuity payout relative to the actuarially fair annuity (right axis) as a function of mandatory annuitized wealth fraction.

The solid line shows that increasing the fraction of mandatory annuitization monotonically crowds out private annuity transaction volumes. Annuitized wealth starts at $32 \%$ in the unconstrained lump sum case (labeled "0\%") and continues to drop, with only $10 \%$ of remaining wealth being annuitized privately when $90 \%$ of pension wealth is required to be annuitized. The equilibrium annuity price changes nonmonotonically as policies change. Annuity generosity decreases 
as the fraction of wealth in a mandatory annuity rises from $0 \%$ to $50 \%$. This is consistent with adverse selection, meaning that retirees who already have $50 \%$ of their wealth in an actuarially fair annuity have a lower willingness to pay for additional annuitization than those who have no money in an annuity. Interestingly, annuity payouts improve when moving from $50 \%$ to $75 \%$ mandatory annuitization, and improve further when moving to $90 \%$. Demand is still contracting in each of these shifts, as reflected by the falling annuitization rate, so it must be the case that the increase in payouts is coming from a more advantageously selected annuitant population. That is, the effect of additional amounts in the mandatory annuity on equilibrium prices are moderated by advantageous selection.

\subsection{Welfare}

The welfare effect of reforming the system is theoretically uncertain. Individuals with strong preferences for full annuitization in all cases have higher welfare with higher mandatory annuitization, since those annuities are actuarially fair. Other individuals' welfare depends on the tradeoff between more unconstrained wealth due to the elimination of PW and forced annuitization that may be unwanted. To sign these overall effects and to measure the distribution of gains and losses, we quantify the welfare comparison between the baseline Chilean system and its reformed versions.

To do so, we calculate for each type their equivalent variation, or the transfer into their baseline pension balance that would make them indifferent between retiring under the baseline or the reformed rules. More precisely, define $V_{B}^{*}\left(W_{0}, \theta_{r}\right)$ to be type $\theta_{r}$ 's utility derived from their optimal allocation of pension balance $W_{0}$ across programmed withdrawal and an annuity at the baseline equilibrium price, and define $V_{R x \%}^{*}\left(x \% \cdot W_{0},(1-x \%) \cdot W_{0}, \theta_{r}\right)$ to be type $\theta_{r}$ 's utility derived from their optimal allocation of remaining pension balance $(1-x \%) \cdot W_{0}$ across lump sum withdrawal and an annuity at the equilibrium price when $\mathrm{x} \%$ of funds are placed in a mandatory annuity. This 
latter utility, of course, takes into account that $x \% \cdot W_{0}$ is returned to retirees through an actuarially fair annuity. Then the equivalent variation for type $\theta_{r}$ between the baseline and the reformed system with $\mathrm{x} \%$ allocation to the mandatory annuity solves

$$
V_{B}^{*}\left(W_{0}+E V\left(x \%, \theta_{r}\right), \theta_{r}\right)=V_{R x \%}^{*}\left(x \% \cdot W_{0},(1-x \%) \cdot W_{0}, \theta_{r}\right)
$$

We plot the resulting distribution of equivalent variation for the unconstrained lump sum and the $50 \%$ mandatory annuitization reforms in Figure 13 . The plot shows that moving to an unconstrained lump sum outside option, which increases the value of the outside option to all retirees, would causes a welfare loss equivalent to $\$ 5,000$ or less for $45 \%$ of our sample. Another $45 \%$ see modest welfare gains from the reform. Finally, about $10 \%$ of our retirees see large welfare benefits from releasing constraints on drawdown. These retirees are high mortality, low outside wealth, and zero bequest motive types. They choose PW in the baseline as it is front-loaded relative to the annuity, but would prefer an option that allows them to consume more and leave less money upon their death. On average, the reform improves welfare, but those gains are driven by a small fraction of the population. The effect of introducing 50\% mandatory annuitization as the outside option has a different effect. This reform causes lost utility for the just $25 \%$ of our sample, though they face a larger magnitude of loss up to $\$ 18,000$ in wealth equivalent. The remaining $75 \%$ benefit from the reform, in wealth equivalents between $\$ 3,000$ and $\$ 30,000$. Mandatory annuitization has a more evenly distributed effect compared to the unconstrained lump sum case.

Then, we compare the distribution of welfare benefits and costs across different levels of mandatory annuitization. The left panel of figure 14 plots the cumulative distribution functions of equivalent variation for third quartile females across different values of the fraction of wealth in the mandatory annuity, while the right panel plots the average and median EV for each counterfactual equilibrium. 


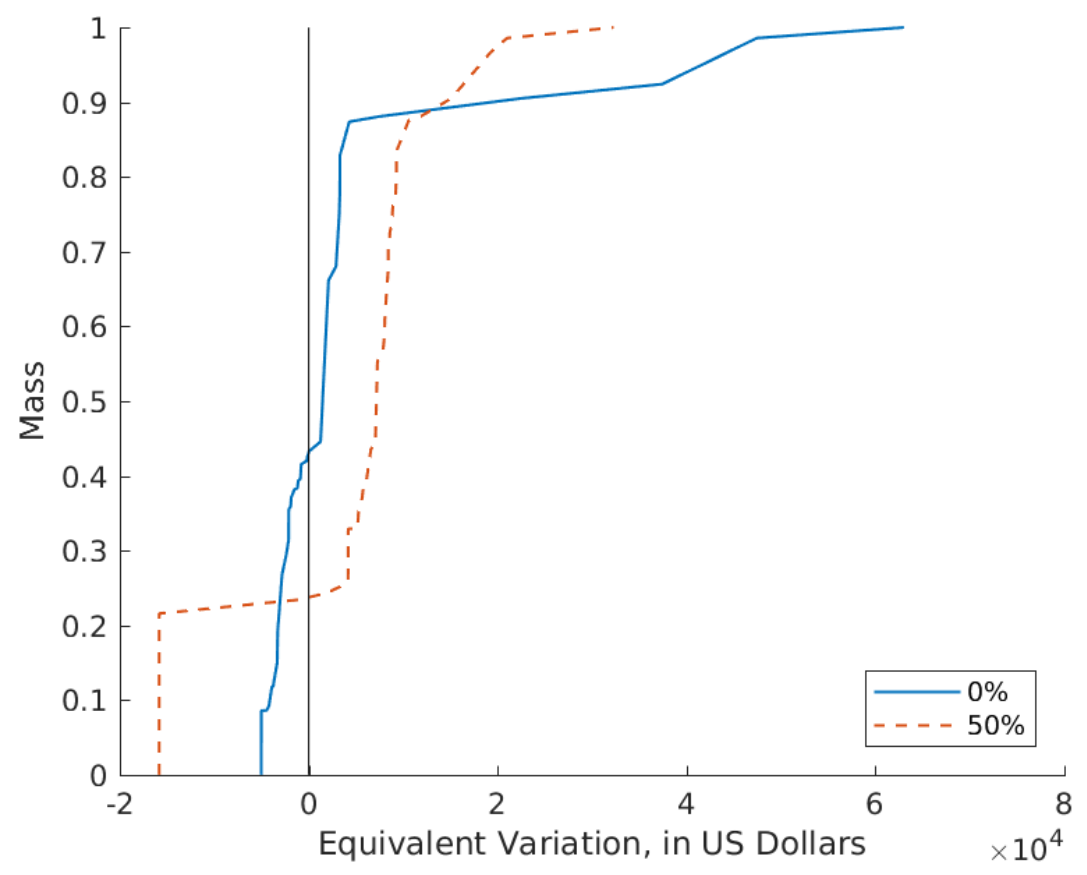

Figure 13: CDF of equivalent variation, for third quartile females, for unconstrained lump sum and $50 \%$ mandatory annuity reform.
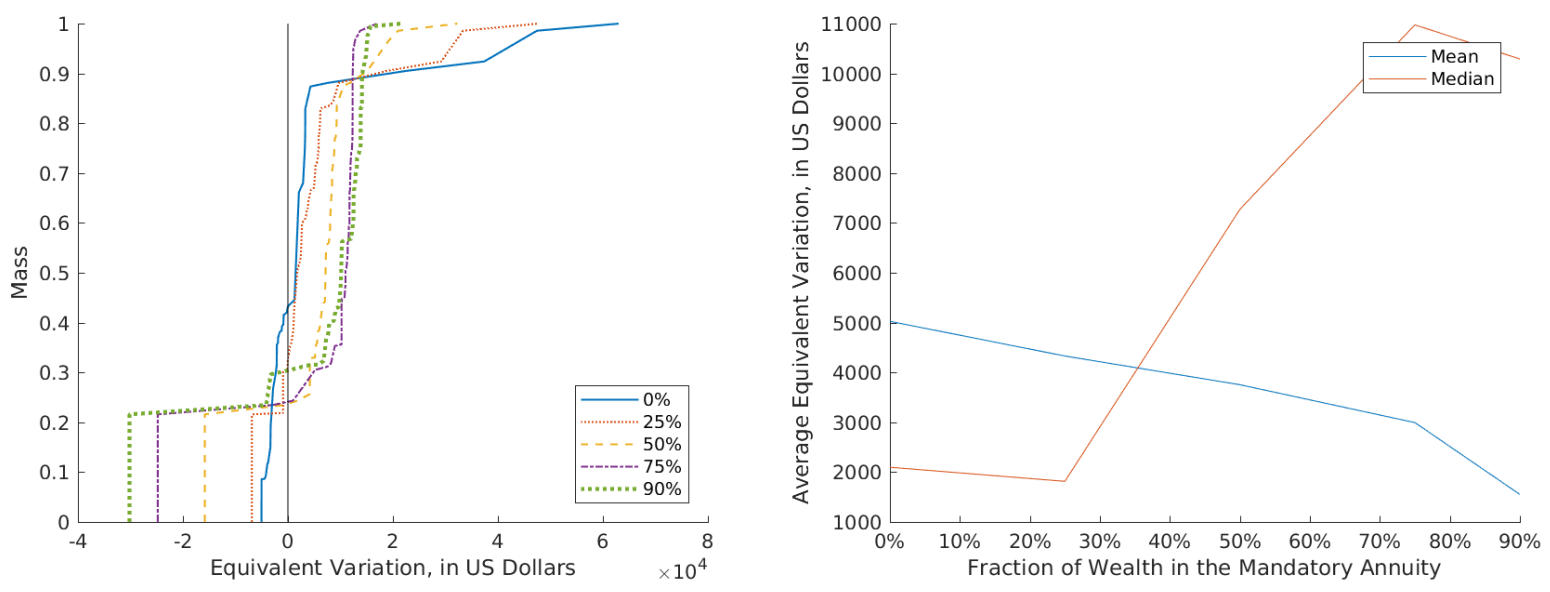

Figure 14: CDF of equivalent variation (left) and mean equivalent variation (right), for third quartile females, across different amounts in the mandatory annuity. 
Focusing on the right panel, the average equivalent variation is positive for all values of wealth in the mandatory annuity, suggesting that on average retirees would prefer any version of the reformed system to the baseline Chilean case. Moreover, the $0 \%$ mandatory annuitization case, where the outside option is changed to lump-sum withdrawal but the system is otherwise unchanged, yields the highest average equivalent variation: on average, retirees would value it equivalently to an increase in their pension balance of 5,000 dollars in the baseline. As the fraction of wealth in the mandatory annuity increases, the average equivalent variation monotonically decreases.

However, the CDFs presented on the left panel of figure 14 highlight that this average equivalent variation masks significant heterogeneity across the population. In fact, no version of the reformed system Pareto dominates the baseline equilibrium, as there is significant mass in both the space where retirees prefer the baseline to the reformed (negative values of EV) and in the space where the converse holds. For example, the distribution of EV when $50 \%$ of wealth in placed in the mandatory annuity exhibits retirees who are are indifferent between this reformed system and being given around $\$ 30,000$ dollars in the baseline and individuals for whom the transfer that would make them indifferent is around $-\$ 16,000$. Returning to the right panel, the very different pattern exhibited by the median of the EV distribution highlights this heterogeneity. Median welfare is lowest when mandatory annuitization is set at $0 \%$ or $25 \%$. Median welfare grows through $50 \%$ mandatory annuitization, and peaks at $75 \%$ mandatory annuitization. Depending on the social welfare function, different levels of mandatory annuitization maximize overall retiree welfare.

\subsection{Discussion}

The previous results show that reforming the system to incorporate mandatory annuitization of a fraction of wealth, combined with a relaxation of the drawdown path for the alternative to 
annuitization, has the potential to increase welfare for the average retiree, although no reform is Pareto improving. There are three natural concerns with these results.

First, we have not modelled the contribution phase of this retirement system, and any reforms will have implications on savings during the working life. This argument does not invalidate this exercise if the objective is to study what soon-to-be retirees would choose in a counterfactual system, as they do not have the ability to greatly change their pension savings or their outside wealth in response to the reform. However, it does cast doubt on the ability to make statements about welfare for individuals who have the time to respond to the reform by significantly changing their savings. We believe that this is an interesting question for future research.

Second, we have not introduced behavioral biases into the model, and as a result cannot speak to time inconsistencies that can arise from having a large sum of money immediately available. To that end, perhaps the introduction of both lump sum withdrawal and mandatory annuitization of a small fraction of pension balances is more desirable than a system with no mandatory annuitization, even though the latter delivers a higher average welfare change.

Finally, one can argue that the natural welfare metric here should be Rawlsian, as the objective of pension systems is to insure a consumption floor for all individuals in the population. Therefore, one should assess the previous findings through the lens of their effects on the welfare of the poorest individuals in the population, and not on the average. To explore this issue, figure 15 presents the same distributions of equivalent variation as before, but now conditioning on the types with the lowest levels of inside and outside wealth - the poorest individuals in our sample. For this subpopulation, we find that reforming the system to include lump sum withdrawal and mandatory annuitization of a fraction of wealth between $25 \%$ and $75 \%$ yields a Pareto improvement relative to the baseline. 


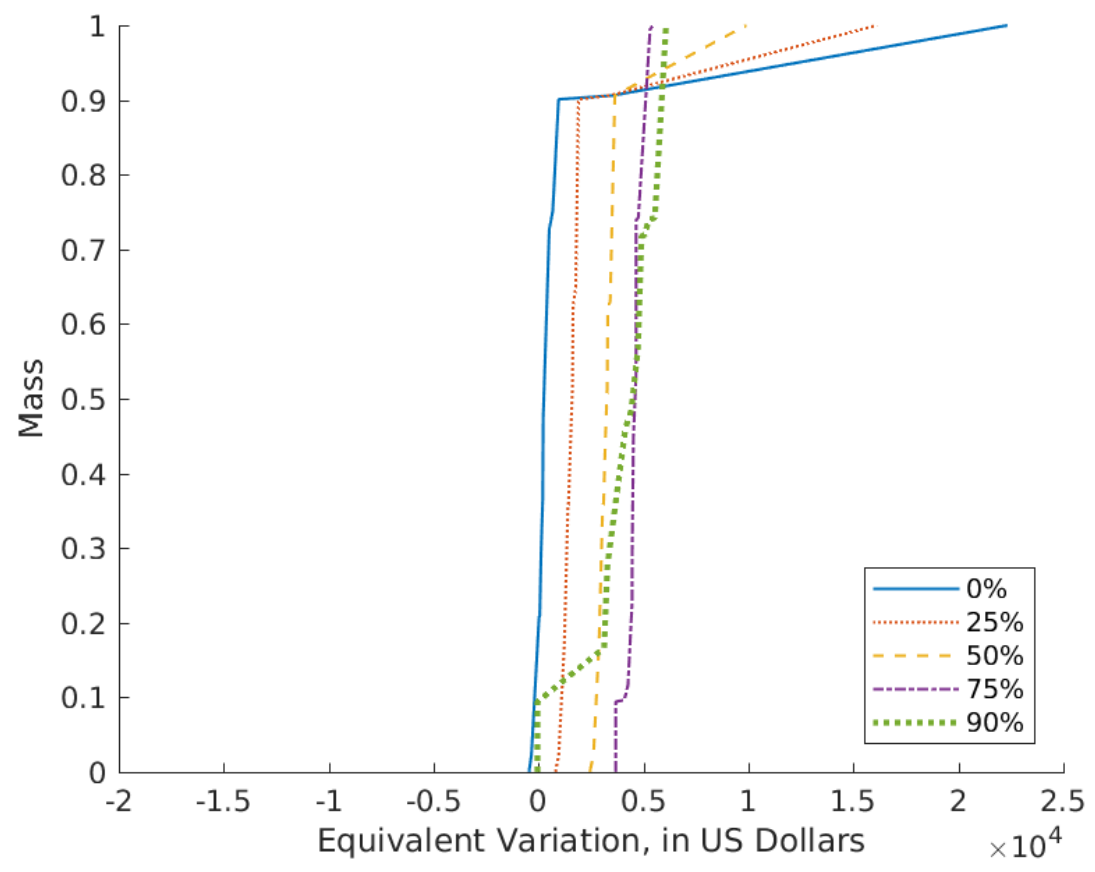

Figure 15: CDF of equivalent variation for first quartile female types with the lowest levels of outside wealth, across different amounts in the mandatory annuity.

\section{Conclusion}

The Chilean annuity market has several striking features. First, a large majority of retirees choose to purchase private annuities with their retirement savings. Second, prices of annuities in equilibrium are 3-5\% more expensive than actuarially fair, significantly cheaper than the 10-15\% markup over actuarial fairness estimated in the US. Third, the Chilean market exhibits evidence of adverse selection, as do many other annuity markets.

The evidence laid out in the reduced form facts and calibrations imply that, under certain parameters, Chile's annuity market may be crowded in by the absence of a public mandatory pension system. That is, the market could unravel if retirement policy was reformed to remove retirees' choice between constrained withdrawal and private annuitization, and replace it with a mandatory system. Furthermore, the shape of the demand and average cost curves found in the calibration 
exercise make it clear that simple reduced form estimation approaches are not well suited to determine whether the market will unravel under counterfactual regulatory regimes or to study the welfare implications of these reforms. To overcome these challenges, we build a structural model based on the standard consumption-savings problem faced by retirees, that accounts for income effects and other features of nonlinear utility that influence retirees' choices. The aim is to estimate the distribution of unobservable retiree characteristics from which we can derive their demand for annuities and the cost firms face to insure them. The model adapts the methodology developed by Fox et al. (2011). We pre-solve this lifecycle model for a representative set of consumers over a wide variety of combinations of unobserved preferences. We then estimate the distribution of weights on the distribution of consumers that allows us to match moments observed in the data.

Demand estimates show that individuals have significant and highly varied private information about their own mortality, bequest motives, risk aversion, and outside wealth. Armed with these demand estimates, we simulate market equilibria under existing Chilean policies, as well as under counterfactual retirement policy which removes limits on drawdown of retirement savings and introduces a mandatory pension for all retirees. Though the private annuity market partially unravels if retirement policy is reformed, retiree welfare increases on average. However, this masks significant heterogeneity in the impact of these reforms. Even replacing the constrained "programmed withdrawal" of retirement assets with an unconstrained lump sum, which is a better product for all retirees, causes welfare loss to annuitants who now face higher prices in the crowded out private market. Overall, our results highlight the importance of assessing policy reforms by quantifying both their direct effect on individuals and their indirect crowd-out or crowd-in of private market equilibria. These effects are particularly complicated in markets with multiple dimensions of private information. Our method of nonparametrically estimating demand provides one way forward for evaluating such policies in other contexts, since it allows for any shape of demand and average cost and it allows for the valuation of out of sample products. By solving for the full distribution 
of welfare gains and losses, our method provides the building blocks for policymakers looking to estimate the impact of large scale policy reforms on individuals with highly heterogeneous preferences.

\section{References}

Alcalde, Pilar, and Bernardita Vial. 2017. "Implicit Trade-off in Replacement Rates: Consumer Preferences for Firms, Intermediaries, and Annuity Attributes."

Anderson, Lisa R., and Jennifer M. Mellor. 2008. "Predicting Health Behaviors With an Experimental Measure of Risk Preference.” Journal of Health Economics, 27(7): 1260-1274.

Bernartzi, Shlomo, Previtero Alessandro, and Richard H. Thaler. 2011. "Annuitization Puzzles." Journal of Economic Perspectives, 25(4): 143-164.

Brown, Jeffrey R., and Amy Finkelstein. 2008. "The Interaction of Public and Private Insurance: Medicaid and the Long-Term Care Insurance Market." American Economic Review, 98(3): 1083-1102.

Brown, Jeffrey R., Arie Kapteyn, Erzo F. P. Luttmer, and Olivia S. Mitchell. 2017. "Cognitive Constraints on Valuing Annuities." Journal of the European Economic Association, 15(2): 429462.

Brown, Jeffrey R., Norma B. Coe, and Amy Finkelstein. 2007. "Medicaid Crowd-Out of Private Long-Term Care Insurance Demand: Evidence from the Health and Retirement Survey." Tax Policy and the Economy, 21: 1-34.

Bundorf, M. Kate, and Kosali I Simon. 2006. "The Effects of Rate Regulation on Demand for Supplemental Health Insurance.” American Economic Review, 96(2): 67-71. 
Butler, Monika, and Federica Teppa. 2007. "The Choice Between an Annuity and a Lump Sum: Results from Swiss Pension Funds.” Journal of Public Economics, 91: 1944-1966.

Caliendo, Frank N., Nick L. Guo, and Roozbeh Hosseini. 2014. "Social security is NOT a substitute for annuity markets." Review of Economic Dynamics, 17(4): 739-755.

Carroll, Christopher D. 2006. "The method of endogenous gridpoints for solving dynamic stochastic optimization problems.” Economics Letters, 91(3): 312 - 320.

Carroll, Christopher D. 2011. "Solution Methods for Microeconomic Dynamic Stochastic Optimization Problems."

Castro, Sebastian, Felipe Castro, Jacinta Diestre, and Luis Muñoz. 2018. "Estudio de Mercado sobre Rentas Vitalicias.” División Estudios de Mercado, Fiscalía Nacional Económica.

Chiappori, PierreAndre, and Bernard Salanie. 2000. "Testing for Asymmetric Information in Insurance Markets.” Journal of Political Economy, 108(1): 56-78.

Comisión Asesora Presidencial Sobre el Sistema de Pensiones. 2015. "Informe Final Comisión Asesora Presidencial Sobre el SIstema de Pensiones.” Ministerio del Trabajo y Previsión Social.

Compendio de Normas del Sistema de Pensiones, Capítulo III: Factor Actuarialmente Justo. 2018.

Crivelli, Luca, Massimo Filippini, and Ilaria Mosca. 2006. "Federalism and regional health care expenditures: an empirical analysis for the Swiss cantons.” Health Economics, 15(5): 535-541.

Cullen, Julie Berry, and Jonathan Gruber. 2000. "Does Unemployment Insurance Crowd out Spousal Labor Supply?” Journal of Labor Economics, 18(3): 546-572.

Cutler, David, and Jonathan Gruber. 1996. "Does Public Insurance Crowd out Private Insurance?" 
Davidoff, Thomas, Jeffrey R. Brown, and Peter A. Diamond. 2005. "Annuities and Individual Welfare.” American Economic Review, 95(5): 1573-1590.

Einav, Liran, Amy Finkelstein, and Paul Schrimpf. 2010. "Optimal Mandates and the Welfare Cost of Asymmetric Information: Evidence From the U.K. Annuity Market." Econometrica, 78(3): 1031-1092.

Einav, Liran, Amy Finkelstein, and Pietro Tebaldi. 2019. "Market Design in Regulated Health Insurance Markets: Risk Adjustment vs. Subsidies.” Mimeo.

Finkelstein, Amy, and Kathleen McGarry. 2006. "Multiple Dimensions of Private Information: Evidence from the Long-Term Care Insurance Market." American Economic Review, 96(4): 938-958.

Finkelstein, Amy, Nathaniel Hendren, and Mark Shepard. 2017. "Subsidizing Health Insurance for Low-Income Adults: Evidence from Massachusetts.” National Bureau of Economic Research Working Paper 23668.

Fox, Jeremy T., Kyoo il Kim, and Chenyu Yang. 2016. "A simple nonparametric approach to estimating the distribution of random coefficients in structural models." Journal of Econometrics, 195(2): $236-254$.

Fox, Jeremy T., Kyoo il Kim, Stephen P. Ryan, and Patrick Bajari. 2011. "A simple estimator for the distribution of random coefficients." Quantitative Economics, 2(3): 381-418.

Friedman, Benjamin M., and Mark J. Warshawsky. 1990. "The Cost of Annuities: Implications for Saving Behavior and Bequests.” The Quarterly Journal of Economics, 105(1): 135-154.

Garthwaite, Craig, Tal Gross, and Matthew J. Notowidigdo. 2018. "Hospitals as Insurers of Last Resort.” American Economic Journal: Applied Economics, 10(1): 1-39. 
Gruber, Jonathan, and Kosali I Simon. 2008. "Crowd-out 10 years later: Have recent public insurance expansions crowded out private health insurance?"

Hackmann, Martin B., Jonathan T. Kolstad, and Amanda E. Kowalski. 2015. "Adverse Selection and an Individual Mandate: When Theory Meets Practice." American Economic Review, 105(3): 1030-1066.

Hosseini, Roozbeh. 2015. "Adverse Selection in the Annuity Market and the Role for Social Security." Journal of Political Economy, 123(4): 941-984.

Illanes, Gaston. 2019. "Switching Costs in Pension Plan Choice." Northwestern University Mimeo.

Keane, Michael, and Olena Stavrunova. 2016. "Adverse selection, moral hazard and the demand for Medigap insurance.” Journal of Econometrics, 190(1): 62-78.

Koch, Thomas G. 2014. "Bankruptcy, Medical Insurance, and a Law with Unintended Consequences." Health Economics, 23(11): 1326-1339.

Lockwood, Lee. 2012. "Bequest Motives and the Annuity Puzzle." Review of Economic Dynamics, 15(2): 226-243.

Mahoney, Neale. 2015. "Bankruptcy as Implicit Health Insurance.” American Economic Review, 105(2): 710-746.

Mitchell, Olivia S., James M. Poterba, Mark J. Warshawsky, and Jeffrey R. Brown. 1999. "New Evidence on the Money's Worth of Individual Annuities." American Economic Review, 89(5): 1299-1318.

Pino, Francisco. 2005. "Retiros Programados y Nuevas Tablas de Mortalidad." Superintendencia de Pensiones Nota Técnica 1. 
Reichling, Felix, and Kent Smetters. 2015. "Optimal Annuitization with Stochastic Mortality and Correlated Medical Costs.” American Economic Review, 105(11): 3273-3320.

Rothschild, Casey G. 2009. “Adverse Selection in Annuity Markets: Evidence from the British Life Annuity Act of 1808.” Journal of Public Economics, 93(10): 776-784.

Sapelli, Claudio. 2016. Chile ¿más equitativo?: Una mirada a la dinámica social del Chile de ayer, hoy y mañana. . 2 ed., Ediciones UC.

Shiller, Robert J. 1998. "Indexed Units of Account: Theory and Assessment of Historical Experience.” National Bureau of Economic Research Working Paper 6356.

Shu, Suzanne B., Robert Zeithammer, and John W. Payne. 2016. "Consumer Preferences for Annuity Attributes: Beyond Net Present Value." Journal of Marketing Research, , (53): 240262.

Sloan, Frank A., and Edward C. Norton. 1997. "Adverse Selection, Bequests, Crowding Out, and Private Demand for Insurance: Evidence from the Long-term Care Insurance Market." Journal of Risk and Uncertainty, 15(3): 201-219.

Starc, Amanda. 2014. "Insurer pricing and consumer welfare: evidence from Medigap." The RAND Journal of Economics, 45(1): 198-220.

Tebaldi, Pietro. 2019. "Estimating Equilibrium in Health Insurance Exchanges: Price Competition and Subsidy Design under the ACA.” Mimeo.

Torche, Florencia. 2005. "Unequal but Fluid: Social Mobility in Chile in Comparative Perspective." American Sociological Review, 70(3): 422-450.

Vega, George. 2014. “Capital Necesario Unitario (CNU): Cálculo e Introducción delMódulo de Stata cnu.” Superintendencia de Pensiones Nota Técnica. 